\title{
Antibacterial polymeric nanocomposites synthesized by in-situ photoreduction of silver ions without additives inside biocompatible hydrogel matrices based on $N$-isopropylacrylamide and derivatives
}

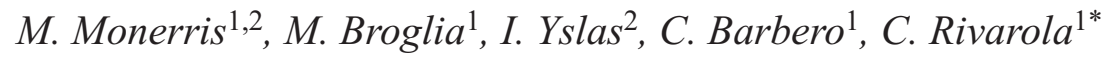 \\ ${ }^{1}$ Chemistry Department, Faculty of Exact, Physical-Chemical and Natural Sciences, National University of Río Cuarto, \\ National Route 36 Km 601, X5804ZAB Rio Cuarto, Córdoba, Argentina, CONICET \\ ${ }^{2}$ Molecular Biology Department, Faculty of Exact, Physical-Chemical and Natural Sciences, National University of \\ Río Cuarto, National Route 36 Km 601, X5804ZAB Rio Cuarto, Córdoba, Argentina, CONICET
}

\begin{abstract}
Synthesis of antibacterial nanocomposite obtained by in-situ photoreduction of $\mathrm{Ag}^{+}$ions impregnated inside a biocompatible hydrogel matrix is described. Hydrogel matrixes based on $N$-isopropylacrylamide (PNIPAM) and copolymers are synthesized by free radical polymerization in aqueous medium. The hydrogels are loaded with $\mathrm{Ag}^{+}$ions and then silver nanoparticles (Ag-NPs) are obtained in-situ by application of UV light without using additives. Ag-NPs formation inside hydrogels is confirmed by UV-visible spectroscopy, scanning electronic microscopy (SEM) and transmission electronic microscopy (TEM). An extensive characterization of nanocomposites is performed by determining the partition coefficient of $\mathrm{Ag}^{+}$ions before photoreduction, the Ag-NPs mass loaded per gram of hydrogel as a function of irradiation time, swelling capacity and volume phase transition temperature. Fourier Transform Infrared (FTIR) spectra indicate the loss of some functional groups of the polymer backbone during reduction of $\mathrm{Ag}^{+}$ions whereas ${ }^{13} \mathrm{C}$ NMR spectra do not show any change in the main carbon chain. Nanocomposites show antibacterial activity against Pseudomonas aeruginosas by release of $\mathrm{Ag}^{+}$ ions while Ag-NPs remain inside matrix. Reducing/stabilizing character of hydrogel and antibacterial activity of nanocomposite depend on the chemical composition of the matrix.
\end{abstract}

Keywords: nanocomposites, reductant/stabilizer hydrogel, silver nanoparticles, photoreduction, antibacterial capacity

\section{Introduction}

Polymeric nanocomposites are obtained by dispersing nanoparticles inside a polymeric network matrix. Then, the properties of nanocomposite materials depend not only on the properties of their individual components but also on the morphology and interfacial characteristics of each of them. Hydrogels are crosslinked polymers with high capacity to absorb aqueous solution and are used as polymeric matrix of nanocomposites. These materials swelling in water present porosity called 'molecular porosity' of size less than $100 \mathrm{~nm}$ [1] or could contain meso-macroporosity according to the synthetic method [2]. Therefore, small molecules or solid nanoparticles, biological or synthetic macromolecules could enter to matrix depending on pore sizes. On the other hand, it has been demonstrated that many hydrogels are biocompatible so they are being used for several biotechnological and biomedical applications $[1,2,3]$. For this reason, these materials are good candidates as polymeric matrices of biocompatible nanocomposites. 
If the pore size of swollen hydrogel is big enough for the incorporation of nanoparticles, then the formation of a stable nanocomposite could be possible. But if the nanoparticle size is bigger than pore size of matrix the nanocomposite formation would not be achievable. However, there are several alternatives to form nanocomposites: i) by interpenetration of linear polymer inside another network polymer [4], ii) by absorption of nanoparticles during swelling of matrix [5] or iii) by incorporation of nanoparticles during the process of polymerization [6]. In addition, it has been demonstrated that nanoparticle size greater than $100 \mathrm{~nm}$ can form stable nanocomposites by absorption during the swelling of a macroporous matrix of hydrogel [6].

Generally, nanoparticle synthesis in solution involves the presence of a stabilizer which implied an increase of size and hydrodynamic radio of particles. But, when the stabilizer is thermosensitive as in the case of poly- $N$-isopropylacrylamide (PNIPAM), the change of NP size by temperature increase has been clearly demonstrated. When PNIPAM as stabilizer collapsed, the NP size decreased approximately 100 $\mathrm{nm}$ regarding not collapsed PNIPAM [7]. This size variation could be a disadvantage for nanocomposite fabrication.

On the other hand, studies about silver nanoparticles [8] indicate that the properties and applicability of the Ag-NPs are drastically influenced by their size, shape, and optical properties. So, it has been demonstrated that bactericidal properties of Ag-NPs depend on size [9].

We are interested in building biocompatible and antibacterial nanocomposites avoiding the use of a stabilizer and taking advantage of physicochemical properties of biocompatible hydrogels [10] to synthesize inside these antibacterial Ag-NPs. Thereby, these nanocomposite materials could be used as cell scaffold and bio-protective materials able to maintain a pollution free system (cells, foods, etc) for future biomedical applications. The fabrication and study of bactericidal nanomaterials are particularly opportune since the amount of new resistant strains to the most potent antibiotics has increased [11].

In order to avoid the use of strong reducing agents such as citrate or $\mathrm{NaBH}_{4}$ and stabilizers not appropriate to biomedical applications, we propose to synthesize Ag-NPs inside hydrogel by photochemical methods without the using of chemical additives. Reducing agents and other materials used during synthesis can leave chemical debris on the materials while the light is simply turned off at the end of the synthesis. However, photochemical synthesis shows little control over size and shape of particle depending on irradiation time, the use of reducing agents to form the initial core of Ag-NP and of stabilizing agents [12].

Our hypothesis suggests the formation of Ag-NPs by photochemical reaction inside hydrogel matrix which would be able to act as reductant of $\mathrm{Ag}^{+}$ions and stabilizer agent of NPs to avoid the presence of toxic chemical reactive. This paper describes an eco-friendly synthetic method to obtain polymeric nanocomposites by in-situ synthesis of Ag-NPs without adding soluble stabilizer and reducing agent. The formation of Ag-NPs is observed by UV-Visible spectroscopy. The physicochemical (swelling and phase transition temperature) properties of formed nanocomposite corroborate the existence of interactions between the matrix and the NPs and ascertain that hydrogel matrix acts as stabilizer of NPs. SEM and TEM spectra show the agglomeration of Ag-NPs, therefore the effect of $\mathrm{AgNO}_{3}$ concentration and irradiation time on NPs formation is analyzed. FTIR spectra show change in band intensity of some functional groups of matrix indicating that they are acting as reducing agent whereas ${ }^{13} \mathrm{C}$ NMR spectra indicate that the main chain of matrix is not chemically altered during irradiation. Antibacterial capacity against the pathogen Pseudomonas aeruginosa is demonstrated. The Ag-NPs-hydrogel composites release $\mathrm{Ag}^{+}$ions when they are swollen in aqueous and physiological medium, then act as antibacterial agent. The release rate of $\mathrm{Ag}^{+}$ions and antibacterial capacity of nanocomposite depends on chemical composition of matrix. The encapsulation of Ag-NPs inside swollen hydrogel in culture medium avoids the dispersion of $\mathrm{Ag}-\mathrm{NPs}$ and regulates the antibacterial agent release rate $\left(\mathrm{Ag}^{+}\right.$ions). This behavior would allow applying these systems as antibacterial cell scaffolds. This synthetic method avoids the use of non biocompatible stabilizers and/or reductants making it suitable for application in biomedicine.

\section{Materials and methods 2.1. Reactive}

Hydrogels of $N$-isopropylacrylamide (NIPAM) (Scientific Polymer Products, Inc., United States) and copolymers with $N$-hydroxyethylacrylamide (HEAA) (Sigma-Aldrich, Argentina), (3-Acrylamidopropyl) 


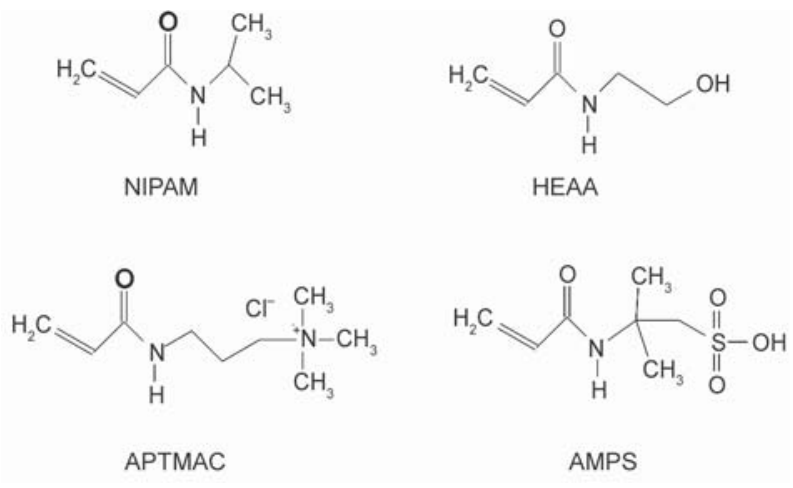

Figure 1. Chemical structure of the monomers

trimethylammonium chloride (APTMAC) (SigmaAldrich, Argentina) and 2-acrylamido-2-methylpropanesulfonic acid (AMPS) (Scientific Polymer Products, Inc (United States)) were synthesized via free-radical polymerization. $N, N^{\prime}$-methylenebis(acrylamide) (BIS) (Sigma-Aldrich, Argentina) was used as crosslinking agent. Ammonium persulfate (APS) (Sigma-Aldrich, Argentina) and $N, N, N^{\prime}, N^{\prime}$-tetramethylenediamine (TEMED) (Sigma-Aldrich, Argentina) were used as the initiator and activator of polymerization, respectively. Figure 1 represents the chemical structure of the monomers used.

\subsection{Polymer and copolymers synthesis}

PNIPAM and copolymers were synthesized dissolving in aqueous solution the monomers of NIPAM $(0.5 \mathrm{M})$ and the respective co-monomer. Proportion of monomeric components are described in Table 1. In all cases, $2 \%$ moles of BIS regarding moles of NIPAM, were used as a cross-linking agent. Next, polymerization initiator system (APS $-0.001 \mathrm{~g} / \mathrm{mL}$ and TEMED $-10 \mu \mathrm{L} / \mathrm{mL}$ ) was added to the precursor solution; $\mathrm{O}_{2}$ was removed by bubbling with $\mathrm{N}_{2}$ gas. The polymerization was carried out at room temperature $\left(22 \pm 2^{\circ} \mathrm{C}\right)$ during $3 \mathrm{~h}$ within test tubes of $1 \mathrm{~cm}$ diameter in order to obtain pills of hydrogels. When the polymerization was completed, the hydrogels were immersed in distilled water at room temperature for $48 \mathrm{~h}$ and the water was renewed several times in order to remove unreacted chemicals.

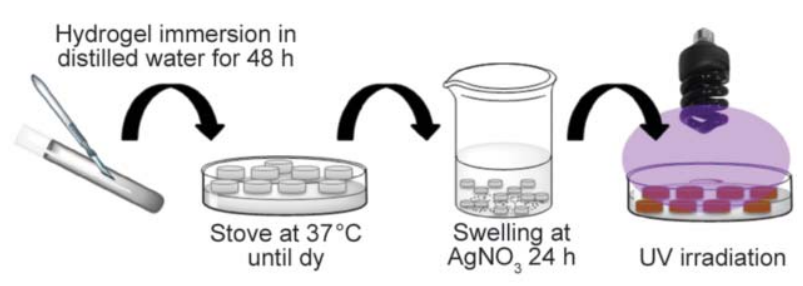

Figure 2. Experimental design of nanocomposite formation by in-situ photoreduction of $\mathrm{Ag}^{+}$ions

\subsection{Nanocomposite formation by in-situ photosynthesis of NPs}

Experimental design to nanocomposite formation is described in Figure 2. Dry hydrogel pills ( $\sim 0.010$ grams each one) were submerged in $3 \mathrm{~mL}$ of $\mathrm{AgNO}_{3}$ solution at two different concentrations $(0.1$ and $0.01 \mathrm{M})$ during $24 \mathrm{~h}$ to ensure that the maximum swelling was reached. Swollen pills have a size around $1.0 \pm 0.1 \mathrm{~cm}$ of diameter and $0.20 \pm 0.05 \mathrm{~cm}$ of thickness. Then UV light was applied to swollen hydrogels in solution of $\mathrm{AgNO}_{3}$ during 18, 24, 42 and $48 \mathrm{~h}$ in order to define the time required to obtain higher concentration of Ag-NPs inside hydrogel. Similar process was carried on each kind of hydrogel. The fluorescent UV lamp (E27 black, Alic SA, Argentina) used has the following characteristics: power: $20 \mathrm{~W}$, frequency: $50 \mathrm{~Hz}$.

Amount of Ag-NPs obtained inside hydrogel were determined as a function of irradiation time by subtraction between weight of dry materials with and without NPs and were expressed as milligrams Ag-NPs/grams hydrogel.

\subsection{Swelling kinetic experience of matrix with and without NPs}

A dry sample of hydrogel (around 0.010 grams), previously washed and weighed, was placed in $5 \mathrm{~mL}$ of distilled water $(\mathrm{pH} 6.5)$ at room temperature $\left(22 \pm 2^{\circ} \mathrm{C}\right)$. The sample was removed from solution, at certain time intervals, and was superficially dried with tissue paper, weighed on analytic balance and placed back into the bath. The measurements were repeated until a constant weight was achieved. The swelling

Table 1. Molar proportion of NIPAM and co-monomers

\begin{tabular}{|l|c|c|c|c|}
\hline \multicolumn{1}{|c|}{ HYDROGELS } & $\begin{array}{c}\text { NIPAM } \\
(\boldsymbol{P M}=\mathbf{1 1 3 . 1 6} \mathbf{~} / \mathbf{m o l})\end{array}$ & $\begin{array}{c}\text { AMPS } \\
(\boldsymbol{P M}=\mathbf{2 0 7 . 2 5} \mathbf{g} / \mathbf{m o l})\end{array}$ & $\begin{array}{c}\text { APTMAC } \\
(\boldsymbol{P} \boldsymbol{M}=\mathbf{2 0 6 . 7 1} \mathbf{g} / \mathbf{m o l})\end{array}$ & $\begin{array}{c}\text { HEAA } \\
(\boldsymbol{P} \boldsymbol{M}=\mathbf{1 1 5 . 1 3} \mathbf{g} / \mathbf{m o l})\end{array}$ \\
\hline PNIPAM & $0.5 \mathrm{M}$ & & & \\
\hline PNIPAM-co-2\% AMPS & $0.5 \mathrm{M}$ & $0.01 \mathrm{M}$ & & \\
\hline PNIPAM-co-6\% APTMAC & $0.5 \mathrm{M}$ & & $0.03 \mathrm{M}$ & \\
\hline PNIPAM-co-8\% HEAA & $0.5 \mathrm{M}$ & & & $0.04 \mathrm{M}$ \\
\hline
\end{tabular}


percentage $(\% S w)$ as a function of time is calculated by Equation (1):

$\% S w_{\mathrm{t}}=100 \cdot \frac{W_{(\mathrm{t})}-W_{(0)}}{W_{(0)}}$

where $W_{(\mathrm{t})}$ represents the weight of hydrogel in swollen state at time $t$ and $W_{(0)}$ is the weight of the dry hydrogel. Graphics of $\% S w$ vs time were made to analyze the swelling kinetic. $\% S w$ data obtained were averaged out at five measurements.

Swelling percentage in equilibrium state $\left(\% S w_{(\mathrm{eq})}\right)$ represents the maximum capacity of the hydrogel and corresponds to plateau of kinetic curve. In addition, the initial slope in the lineal range (from zero to 125 minutes approximately) is considered to estimate the initial responsive rate $\left(R_{\mathrm{i}}\right)$ of the material. The aim of this experience is to evaluate how the kinetic parameters of hydrogels are affected by chemical composition of nanocomposites.

\subsection{Partition coefficient $(P c)$ determination.}

The distribution of solute $\left(\mathrm{AgNO}_{3}\right)$ between the hydrogel and liquid phase in equilibrium state is defined by the partition coefficient $(P c)$. Equation (2) represents the grams of $\mathrm{Ag}^{+}$ions (solute) loaded per $1000 \mathrm{~g}$ of hydrogel (molal) rationed to the grams of $\mathrm{Ag}^{+}$ions per $1000 \mathrm{~g}$ of aqueous solution (molal) after reaching the equilibrium state:

$P c=\frac{\mathrm{Ag}^{+} \text {molalidad (hydrogel) }}{\mathrm{Ag}^{+} \text {molalidad (water) }}$

Experimentally, a piece of dry hydrogel (around 0.010 grams) of known mass was immersed in $5 \mathrm{~mL}$ of $\mathrm{AgNO}_{3}$ at defined concentration ( $\mathrm{pH}$ 6.5). After $24 \mathrm{~h}$ of immersion the hydrogel was removed and the concentration of $\mathrm{Ag}^{+}$ions remaining in the solution was determined by potentiometric titration with $\mathrm{NaCl}$ solution $(0.01 \mathrm{M})$. Previously, sodium chloride was dried for $2 \mathrm{~h}$ in a drying oven at $120^{\circ} \mathrm{C}$ and allowed to cool down in a desiccator. Potentiometric titration was performed employing an ion-selective electrode $\mathrm{Ag} / \mathrm{AgCl}$ (Methrom AG, Suiza) and Calomel electrode as reference.

Knowing the initial (before swelling) and final moles of $\mathrm{Ag}^{+}$ions (after swelling) in the external solution, the concentration of $\mathrm{AgNO}_{3}$ into hydrogel and water can be calculated and then $P c$ can be estimated. The procedure was repeated in triplicate.

\subsection{UV-visible spectroscopy}

The optical properties of NPs in aqueous dispersion and inside hydrogels were studied by UV-visible spectroscopy (Hewlett-Packard- 8453 diode array, Palo Alto, California, USA). Quartz cells (Hellma Analytics, Germany) were used to analyze the external dispersion. To verify the formation of Ag-NPs inside hydrogel, nanocomposite was located between two quartz slides with a separator of $2 \mathrm{~mm}$ and was positioned in the spectrophotometer so that the UVvisible light source passes through the composite, and thus to obtain the absorption spectral.

\subsection{Fourier transform infrared spectroscopy (FTIR)}

FTIR spectra were measured on a Nicolet Impact 400 spectrometer (Nicolet Instrument Corporation, Madison, Wis. USA) by transmission. The dry hydrogels and nanocomposites were crushed and mixed with dry $\mathrm{KBr}$ salt to form pills under pressure and vacuum.

\subsection{Nuclear magnetic resonance spectroscopy (NMR)}

${ }^{13} \mathrm{C}$ NMR spectra were measured on a Bruker BZH 300/89 spectrometer (Bruker Corporation, Germany). Spectra of sample in solid state were taken by crosspolarization with rotation to the magic angle.

\subsection{Scanning electron microscopy (SEM)}

Nanocomposites were dried under vacuum $\left(30^{\circ} \mathrm{C}\right)$ to remove water and they were metallized with gold. Scanning electron micrographs at low vacuum and low field were taken using a Carl Zeiss EVO MA10 SEM (ZEISS, Germany).

\subsection{Transmission electronic microscopy (TEM)}

Transmission electronic micrographs of hydrogels with and without NPs in wet state were taken using a Jeol Jem-1220 transmission electron microscope (Jeol USA).

\subsection{Differential scanning calorimetric (DSC)}

A Netzsch DSC-204-F1-Phoenix differential scanning calorimeter (NETZSCH-Gerätebau GmbH, Germany) equipped with a cooling device was used to measure the volume phase transition temperature 
(VPTT) of hydrogels and nanocomposites under high purity $\mathrm{N}_{2}$ flow. All the samples (around 0.009 grams each) were previously swollen in distilled water until swelling equilibrium state was reached. The DSC curves were obtained by sample cooling $\left(8^{\circ} \mathrm{C} / \mathrm{min}\right)$ from room temperature to $-30^{\circ} \mathrm{C}$ using liquid $\mathrm{N}_{2}$, followed by a reheating at a scanning rate of $8^{\circ} \mathrm{C} / \mathrm{min}$ until reaching $60^{\circ} \mathrm{C}$. The measurement was repeated five times with the same protocol to check the reproducibility. The experimental error of these measurements was $\pm 1{ }^{\circ} \mathrm{C}$.

\subsection{Antibacterial activity studies}

The antimicrobial activity of Ag-NPs against Pseudomonas aeruginosa (ATCC) was tested according to agar diffusion test. Samples were exposed to bacteria in solid media (nutrient agar), and the inhibition zone around each sample was measured and recorded as the antibacterial effect of nanocomposites. This method was performed in Luria-Bertani (LB) medium solid agar Petri dish. Luria-Bertani (LB) medium was used as a growing medium of Pseudomonas aeruginosa bacteria in overnight inoculums. After that, $100 \mu \mathrm{L}$ of bacterial solution was placed over the agar into sterilized Petri dishes. The PNIPAM hydrogels and copolymers with anionic, cationic and neutral monomers were used as control groups. Each hydrogel and corresponding nanocomposites were placed on Pseudomonas aeruginosa cultured agar plate. Agar plate was incubated for $48 \mathrm{~h}$ at $37^{\circ} \mathrm{C}$ and the inhibition zone was monitored. After $48 \mathrm{~h}$ incubation the presence of bacterial growth on agar plates and inhibition halo around the samples were observed. The inhibition halo diameters were measured with a digital caliber. The assays were performed in triplicate.

\section{Results and discussion}

\subsection{Swelling capacity of hydrogels matrix}

Hydrogels based on PNIPAM and copolymers are synthesized by free radical polymerization. Dry hydrogel pills are placed in aqueous solution and the water taken capacity (\%Swelling) is determined in function of time (Equation (1)). Figure 3 shows the swelling kinetic in distilled water for each hydrogel. Swelling kinetic parameters are analyzed (Table 2) by determination of swelling initial rate $\left(R_{\mathrm{i}}\right)$ and swelling percentage in equilibrium state $\left(\% S w_{(\mathrm{eq})}\right)$ or swelling capacity maximum of hydrogels in order to compare the behavior of each material.

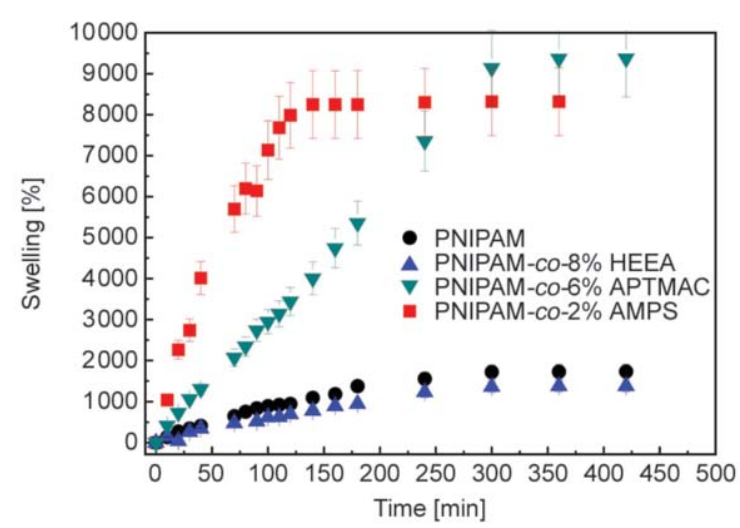

Figure 3. Swelling behaviors of hydrogels in water at room temperature $\left(22 \pm 2^{\circ} \mathrm{C}\right)$ and $\mathrm{pH} 6.5$

Table 2. Kinetic parameters determined from curves of swelling kinetic in water at room temperature $\left(22 \pm 2^{\circ} \mathrm{C}\right)$ and $\mathrm{pH} 6.5$

\begin{tabular}{|l|c|c|}
\hline \multicolumn{1}{|c|}{ HYDROGELS } & $\begin{array}{c}\boldsymbol{R}_{\mathbf{i}}^{\mathbf{a}} \\
{[\mathbf{\%} \boldsymbol{S} \boldsymbol{w} / \mathbf{m i n}]}\end{array}$ & $\mathbf{\%}_{\mathbf{S}} \boldsymbol{w}_{(\mathrm{eq})} \mathbf{b}$ \\
\hline PNIPAM & 9.17 & 1799 \\
\hline PNIPAM-co-8\% HEAA & 6.05 & 1367 \\
\hline PNIPAM-co-2\% AMPS & 59.18 & 8269 \\
\hline PNIPAM-co-6\% APTMAC & 29.90 & 9362 \\
\hline
\end{tabular}

${ }^{\mathrm{a}} R_{2}=0.9987,{ }^{\mathrm{b}}$ Error $= \pm 50$

PNIPAM-co-2\% AMPS (anionic) and PNIPAM-co$6 \%$ APTMAC (cationic) hydrogels show higher swelling capacities. This is due to the ionic moieties $\left(-\mathrm{SO}_{3}{ }^{-} \mathrm{H}^{+}\right.$and $\left.-\mathrm{N}\left(\mathrm{CH}_{3}\right)_{3}{ }^{+} \mathrm{Cl}^{-}\right)$which dissociate and create an overall charge density along the chains, as well as a high concentration of mobile ions inside the hydrogel. When ionic groups are present, two forces appear increasing the hydrogel swelling: i) the osmotic pressure resulting from differences in ion concentration between the swollen gel and the external solution; ii) the electrostatic repulsion (i.e. coulombic) between charged chain segments. Noteworthy, $\% S w_{(\mathrm{eq})}$ and $R_{\mathrm{i}}$ increase with concentration of ionic moieties present in matrix.

When functional groups are able to interact between them by hydrogen bonds $(-\mathrm{NHR},-\mathrm{OH})$ a reduction of the swelling capacity $\left(\% S w_{(\mathrm{eq})}\right)$ is observed, as in the case of PNIPAM and PNIPAM-co- $8 \%$ HEAA. Intramolecular interactions contribute to the formation of more crosslinker points inside matrix, inhibiting the swelling. Therefore, similar tendency is observed for $R_{\mathrm{i}}$ values obtained. This behavior will be compared afterwards with corresponding nanocomposites. 


\subsection{Evidence of nanocomposites obtained by in-situ photochemical synthesis of Ag-NPs}

Hydrogel pills were swelled in a glass capsule containing 0.01 or $0.1 \mathrm{M} \mathrm{AgNO}_{3}$ solutions during $24 \mathrm{~h}$. Then, UV light was applied at different times of irradiation. During irradiation color changes on hydrogels were observed while the external solutions always remained colorless. According to Figure 4, the formations of Ag-NPs inside hydrogel can be qualitatively observed by the color change from yellowish-brown to dark-brown. An effect of irradiation time is remarkable for PNIPAM swollen at $0.01 \mathrm{M}$ of $\mathrm{AgNO}_{3}$ (Figure 4a, while PNIPAM-co-8\% HEAA hydrogels are apparently color saturated at same irradiation time (Figure $4 \mathrm{~b}$ ). Swelling at $0.1 \mathrm{M}$ of $\mathrm{AgNO}_{3}$ solution, all nanocomposites are color saturated at different irradiation time. The other hydrogels synthesized are also visually saturated under the same experimental conditions.

To confirm the formation of Ag-NPs inside hydrogel, the UV-visible spectra of hydrogel and external solutions were determined. Figure 5 shows the spectra of nanocomposites obtained at different times of irradiation swollen in $0.01 \mathrm{M}$ of $\mathrm{AgNO}_{3}$ solution. The distortion of bands is due to heterogeneity of nanocomposites and signal saturation. Two characteristic bands of Ag-NPs surface plasmon resonance situated at 270 and $410 \mathrm{~nm}$ [13] are observed. The last band begins to shift toward red and widens with irradiation time, indicating formation of agglomerated NPs. The spectrum of $\mathrm{AgNO}_{3}$ external solution, inserted in Figure 5a, shows a negligible absorption band in the 400-550 $\mathrm{nm}$ range, what may be due to small detachment of Ag-NPs from hydrogel surface, and other intense absorption band with maximum at $300 \mathrm{~nm}$ corresponding to $\mathrm{AgNO}_{3}$ solution. This suggests that the photoreduction of $\mathrm{Ag}^{+}$ions mainly occurs inside the hydrogel.

Hydrogel loaded with $0.01 \mathrm{M} \mathrm{AgNO}_{3}$ solution and after $18 \mathrm{~h}$ of irradiation shows high absorbance values of Ag-NPs at $410 \mathrm{~nm}$ and a shifting to red in $15 \mathrm{~nm}$ when the irradiation time increases at $24 \mathrm{~h}$ (Figure 5). The shifting and widening of band demonstrate clearly an increase in size and agglomeration of the NPs [13, 14]. Stamplecoskie et al. [14], suggested that the appearance of the broadband in the range $570-700 \mathrm{~nm}$ could be due to the presence of NPs aggregates. Again with the progress of reaction a weak band (shoulder) of around $350 \mathrm{~nm}$ appears due to reflection by increasing Ag-NP particle size [15]. A shifting and widening of band is also observed when hydrogels are loaded in $0.1 \mathrm{M} \mathrm{AgNO}_{3}$ solution. Similar spectral behaviors are observed in other synthesized nanocomposites.

Evidently, high concentrations of in-situ formed AgNPs can be obtained by this method of synthesis achieving high levels of loading. However, the widening and red-shift are evidence of agglomeration of NPs and/or NPs polydispersion formation [16]. Similar behavior was observed when Ag-NPs were synthesized by reduction of $\mathrm{Ag}^{+}$ions with $\mathrm{NaBH}_{4}$ [17], or by reduction with hydrogen [18].

SEM and TEM images of nanocomposites synthesized at different times of irradiation are shown in

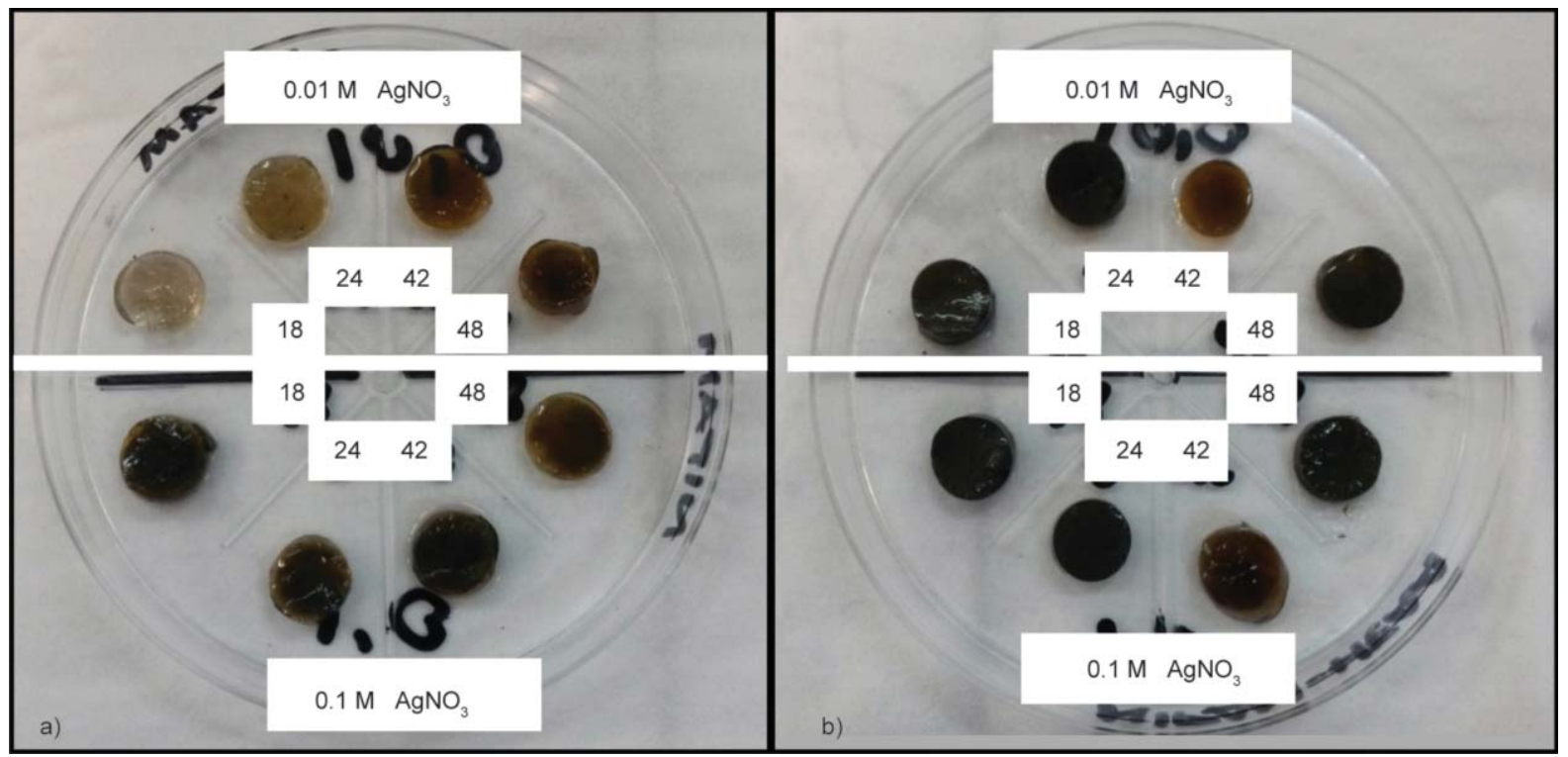

Figure 4. Photography of nanocomposites obtained by in-situ photoreduction of Ag-NPs swollen in $0.1 \mathrm{M}$ (down) and $0.01 \mathrm{M}$ (up) $\mathrm{AgNO}_{3}$ solutions at different irradiation time: 18, 24, 42 and 48 h. (a) PNIPAM, (b) PNIPAM-co-8\% HEAA. 

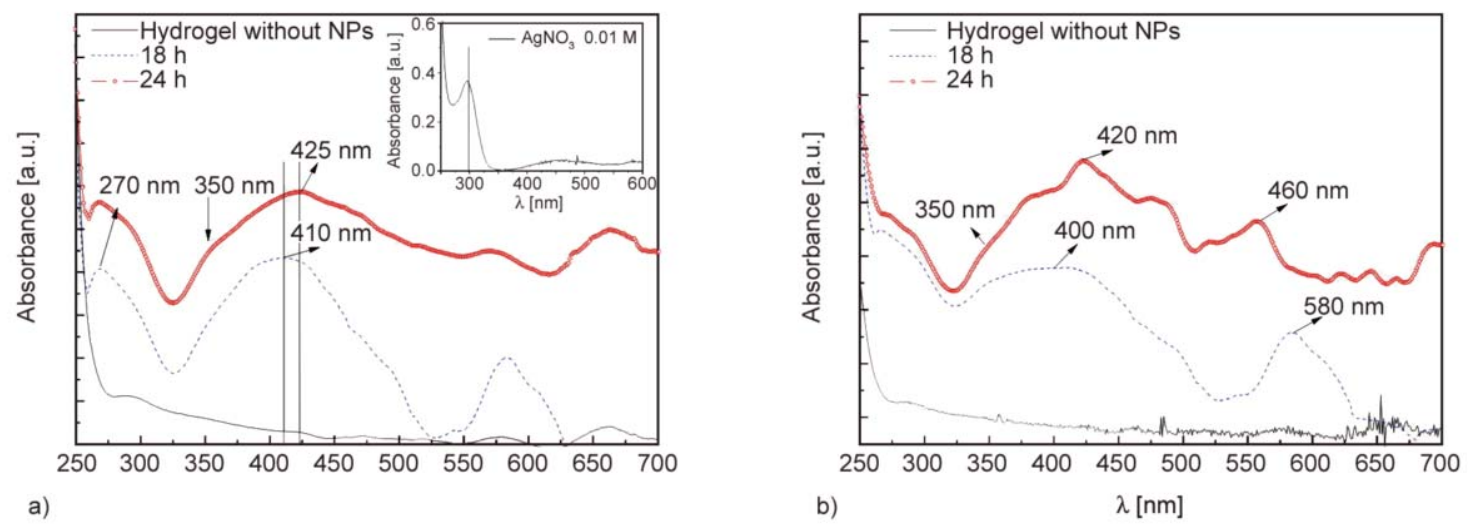

Figure 5. UV-visible spectra of nanocomposites with Ag-NPs obtained in-situ photochemically at different irradiation time by swelling in $0.01 \mathrm{M}$ of $\mathrm{AgNO}_{3}$. a) PNIPAM (insert: UV spectral of extern solution of $\mathrm{AgNO}_{3}$ ) and b) PNIPAMco- $2 \%$ AMPS.

Figure 6. By two spectroscopic techniques, Ag-NPs agglomerates are observed. SEM image in Figure 6a of nanocomposite synthesized at $42 \mathrm{~h}$ of irradiation shows adsorbed Ag-NPs on hydrogel edge with bigger agglomerates of size c.a. $350-400 \mathrm{~nm}$. In an internal cut of the hydrogel, Ag-NPs homogeneously distributed (Figure $6 \mathrm{~b}$ ) can be observed. On the other hand, TEM images of hydrogel synthesized at $8 \mathrm{~h}$ irradiation (Figure 6c, 6d) show Ag-NPs agglomerated inside PNIPAM-co-6\%APTMAC nanocomposite with varying size without defined form, one of around $100 \mathrm{~nm}$, others of around $50 \mathrm{~nm}$ and smaller particles are almost not detected. A wide distribution of size is observed. Figure $6 \mathrm{e}, 6 \mathrm{f}$ shows spherical particles, most of them are smaller particles around $10 \mathrm{~nm}$ and some agglomerates smaller than $50 \mathrm{~nm}$.

Possibility, the wide distribution of size is due to matrix saturation with NPs formed. Evidently, the irradiation time determines the size of agglomerates during reduction reaction of $\mathrm{Ag}^{+}$ions inside matrix. Noteworthy, all the hydrogels matrixes based on NIPAM are able to photoreduce $\mathrm{Ag}^{+}$ions and produce stable silver nanoparticles.

\subsection{Partition coefficient of $\mathbf{A g}^{+}$ions}

It is possible that the concentration of Ag-NPs obtained in nanocomposite depends on initial concentration of $\mathrm{Ag}^{+}$ions inside hydrogel, as well as the chemical composition of matrix. For this reason, it is important to know the partition coefficients of $\mathrm{Ag}^{+}$ ions between hydrogel and water. Partition coefficients $(P c)$ of $\mathrm{AgNO}_{3}$ at $\mathrm{pH} 6.5$ were calculated by potentiometry for each hydrogel synthesized and after $12 \mathrm{~h}$ of swelling when swelling capacity maximum was reached. Values of $P c>1$ indicate that $\mathrm{AgNO}_{3}$ is incorporated mainly into hydrogel. $P c$ calculated of hydrogel loaded with 0.01 and $0.1 \mathrm{M}$ of $\mathrm{AgNO}_{3}$ at $20^{\circ} \mathrm{C}$, are shown in Table 3 .

All hydrogels have capacity to absorb $\mathrm{Ag}^{+}$ions. $P c$ values of metallic ions depend on chemical composition of matrix as it was also observed for other cations such as $\mathrm{Fe}^{+2}[19]$. However, $P C$ values of hydrogels swollen at $0.01 \mathrm{M}$ of $\mathrm{AgNO}_{3}$ are higher than $0.1 \mathrm{M}$ of $\mathrm{AgNO}_{3}$, which may be possible due to effect of ionic strength that inhibits the swelling of hydrogel. Chandrika Pooma et al. [20] demonstrated how the salt concentration effect and kind of salt affect the swelling capacity of hydrogels. In addition, the osmotic pressure resulting from the difference in mobile ion concentration between the hydrogel matrix and the surrounding aqueous phase decreases, adversely affecting swelling and consequently ions incoming.

Possibly, $P c$ values are defined by interactions of $\mathrm{Ag}^{+}$ ions with matrix where ion-dipole and attraction and repulsion electrostatics are present. PNIPAM presents the highest $P c$ value; hence the ion-dipole interactions between $\mathrm{Ag}^{+}$ions and amide group electrons, which predominate into hydrogel, seem to be more important than coulombic attraction and repulsion.

Table 3. Partition coefficients $(P c)$ of $\mathrm{Ag}^{+}$ions determined by potentiometry at $20^{\circ} \mathrm{C}$

\begin{tabular}{|l|c|c|c|c|}
\hline AgNO $_{3}$ solution & PNIPAM & PNIPAM-co-2\% AMPS & PNIPAM-co-8\% HEAA & PNIPAM-co-6\% APTMAC \\
\hline $0.01 \mathrm{M}$ & 59 & 21 & 17 & 35 \\
\hline $0.1 \mathrm{M}$ & 39 & 18 & 5 & 33 \\
\hline
\end{tabular}




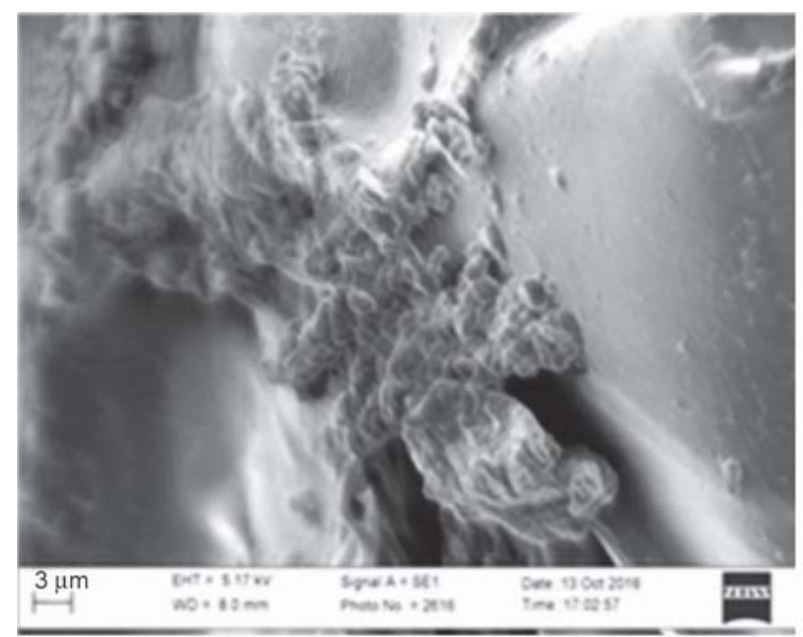

a)

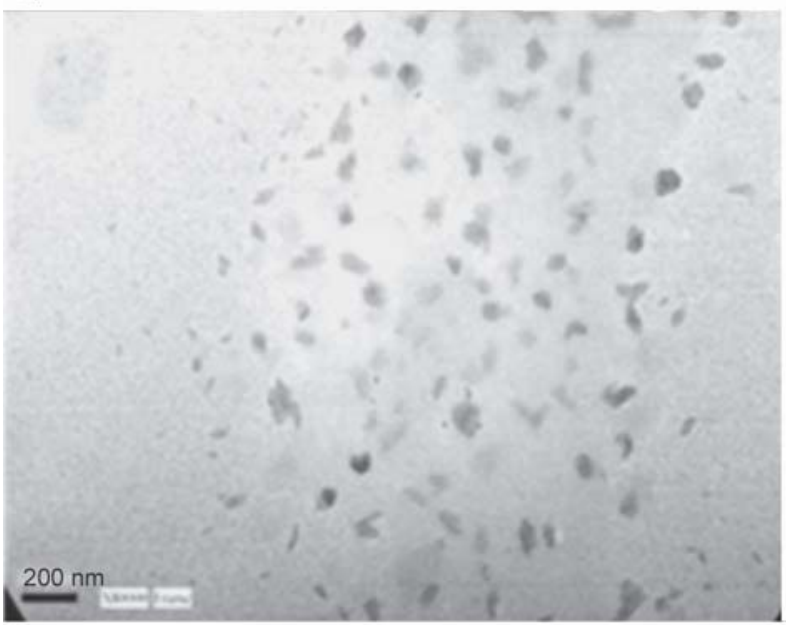

c)

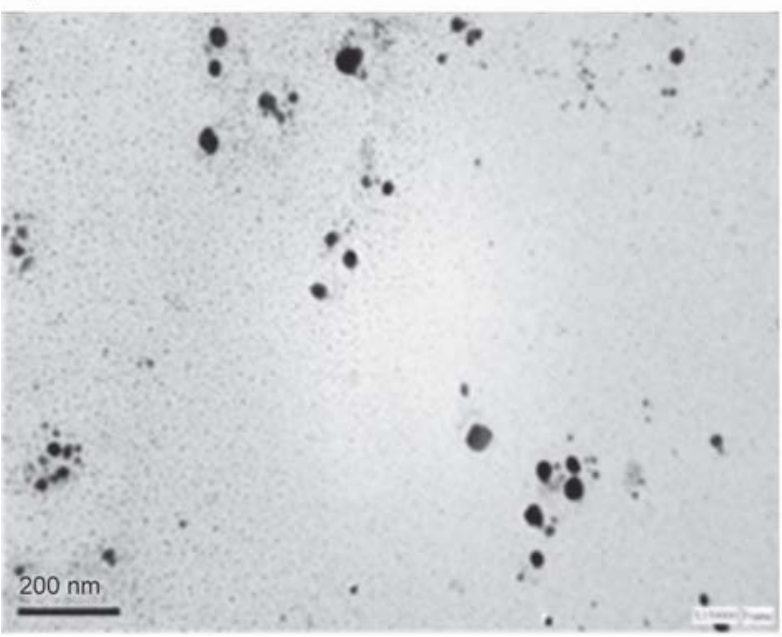

e)

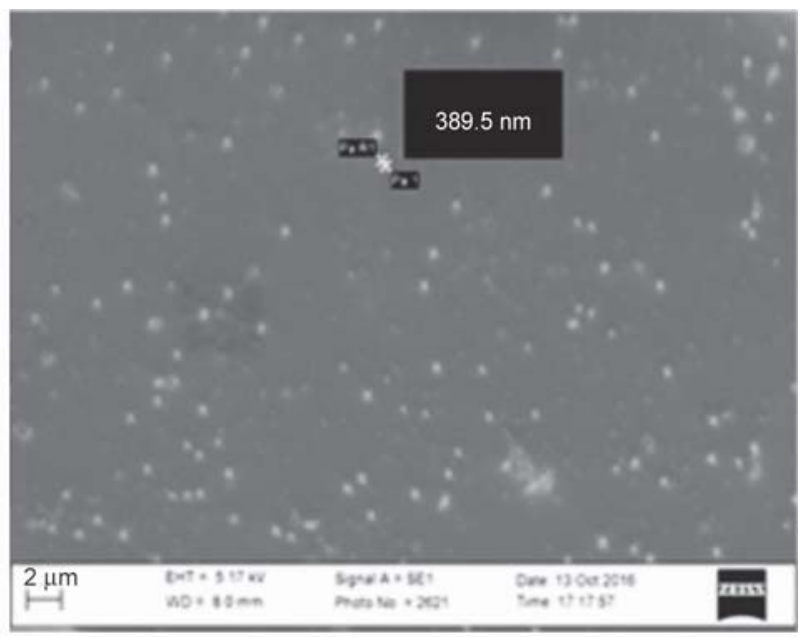

b)

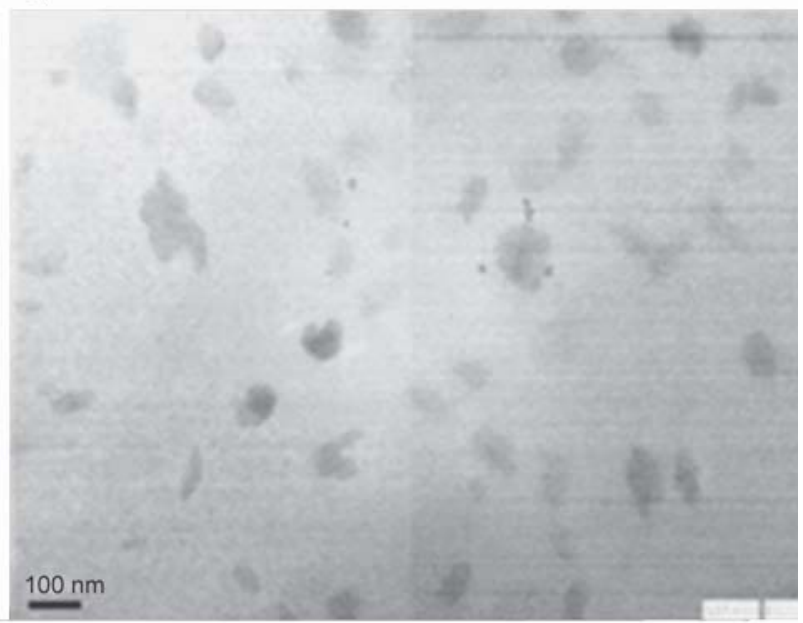

d)

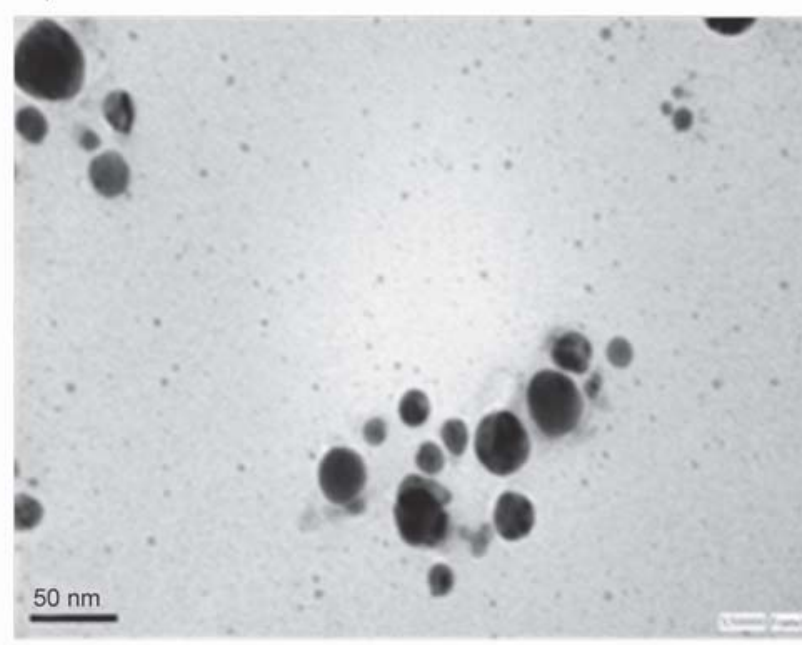

f)

Figure 6. SEM images of Ag-NPs obtained inside hydrogels after $42 \mathrm{~h}$ of irradiation in $0.01 \mathrm{M}$ of $\mathrm{AgNO}_{3}$ : a) edge of PNIPAM pill (scale bar: $3 \mu \mathrm{m}$ ) and b) internal court of PNIPAM pill (scale bar: $2 \mu \mathrm{m}$ ). c, d): TEM images of Ag-NPs obtained in PNIPAM-co-6\%APTMAC after $8 \mathrm{~h}$ of irradiation in $0.01 \mathrm{M}$ of $\mathrm{AgNO}_{3}$ solution. e, f) TEM images of Ag-NPs obtained in PNIPAM-co-2\%AMPS after $8 \mathrm{~h}$ of irradiation in $0.01 \mathrm{M}$ of $\mathrm{AgNO}_{3}$.

\subsection{Load capacity of Ag-NPs and reductant capacity of matrix.}

This analysis is made to determine if the partition capacity of $\mathrm{Ag}^{+}$ions defines the amount of Ag-NPs formed inside hydrogel at same irradiation time. The milligrams of Ag-NPs per grams of hydrogel were determined by gravimetry after swelling at 0.01 and $0.1 \mathrm{M}$ of $\mathrm{AgNO}_{3}$ solutions and at different times of 

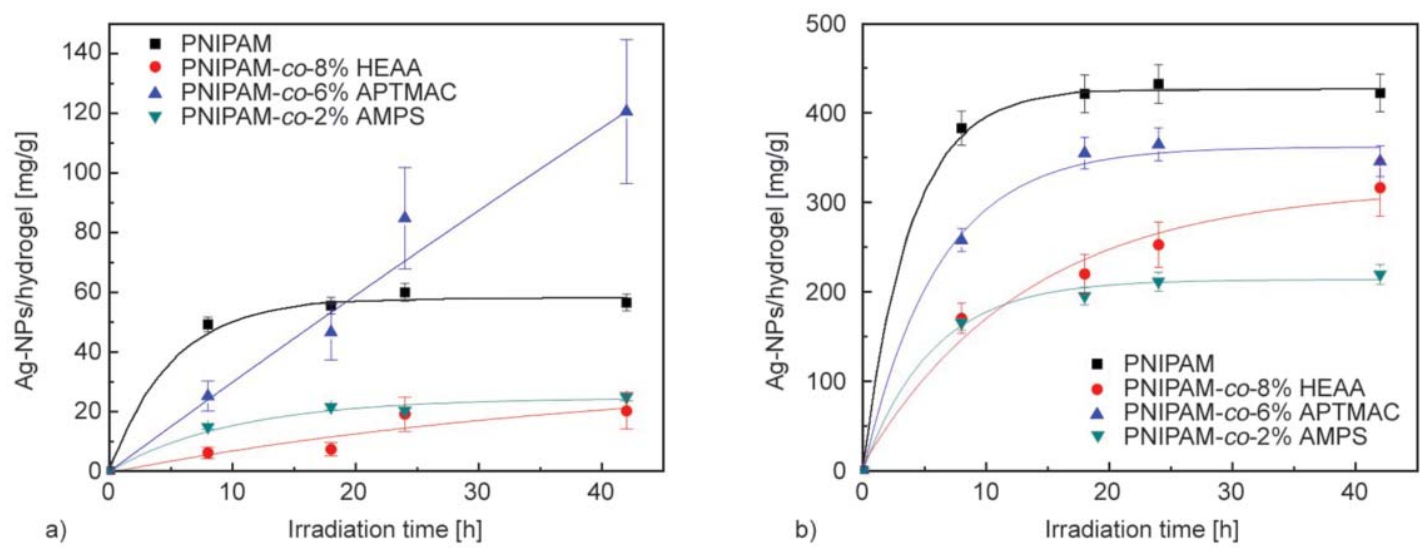

Figure 7. Kinetic of Ag-NPs photochemical formation inside hydrogel matrices in function of time and initial concentration of $\mathrm{AgNO}_{3}$ solutions: $0.01 \mathrm{M}(\mathrm{a})$ and $0.1 \mathrm{M}(\mathrm{b})$

irradiation. Figure 7 shows the kinetic of Ag-NPs milligrams load per grams of hydrogel.

From Figure 7, it can be seen that hydrogels swollen at $0.1 \mathrm{M}$ of $\mathrm{AgNO}_{3}$ solution, contain higher amount of Ag-NPs load at same irradiation time regarding swelling at $0.01 \mathrm{M}$ of $\mathrm{AgNO}_{3}$ solution. In addition, the system saturation point is quickly achieved at $12 \mathrm{~h}$ of irradiation approximately for both initial conditions of $\mathrm{AgNO}_{3}$ solution, except for PNIPAM-co- $6 \%$ APTMAC.

Noticeably, the milligrams of Ag-NPs formed before saturation is directly proportional to the partition coefficient of $\mathrm{Ag}^{+}$ions (Table 3). It is likely that the reaction rate depends directly on the $\mathrm{Ag}^{+}$initial concentration inside hydrogel. In addition, the reducting role of matrix could be due to interaction among $\mathrm{Ag}^{+}$ ions with nonbonding electrons of carbonyl oxygen and nitrogen of NIPAM [21, 22]. Thus, PNIPAM seems to have better photoreducing character.

\subsection{Evidence of the reductant role of the hydrogels}

Considering the chemical composition of studied matrixes, there are reducing groups present in polymeric chain such as hydroxyls, amides and amines which are able to reduce the $\mathrm{Ag}^{+}$ions upon UV light irradiation. It was reported in several cases that the preliminary addition of any metal nanoparticle seeds is required to form NPs but the direct photoreduction of silver cations could also occur by the presence of an excited chromophores or by an intermediate reactant which is generated in-situ during excitation [23]. For example, Malval et al. [24], reported the photoinduced synthesis of monodisperse ligandcoated silver nanoparticles, where $\mathrm{Ag}^{+}$ion was reduced by R-aminoalkyl radicals.
In addition, the most commonly used stabilizers are thiol derivatives [25], ionic or neutral surfactants [26], alkylamines [27], or carboxylic compounds [17], therefore the alkyl chains and other functional groups of hydrogel matrix could be acting as stabilizers of Ag-NPs.

A rearrangement of electronically excited molecules could be possible in photochemistry process; in the sense that they follow reaction pathways that are usually inaccessible in the ground state (activation barriers in the ground state are very high). Knowing that the light absorbed by a molecule can produce photochemical modification in the molecule, FTIR and ${ }^{13} \mathrm{C}$ NMR spectra were obtained for hydrogels and corresponding nanocomposites in order to observe changes on characteristic bands of hydrogels.

In Figure 8 the characteristic bands for PNIPAM are showed and indicated with an arrow while the observed band changes regarding nanocomposite are indicated with squares. The spectra were normalized at $1657 \mathrm{~cm}^{-1}$ corresponding to band I of amides [28]. After $8 \mathrm{~h}$ of irradiation, it is qualitatively notable that there is a decrease of band intensity in range of $3700-3000 \mathrm{~cm}^{-1}$ [29], corresponding to $\mathrm{N}-\mathrm{H}$ signal of secondary amides and amides associated. This was observed in all cases.

In addition, a decline of intensity at $1160-1130 \mathrm{~cm}^{-1}$ [29] is also remarkable which could correspond to $\mathrm{C}-\mathrm{H}$ bending of methyl and methylene groups. However, this was not notable in all cases.

${ }^{13} \mathrm{C}$ NMR spectra of the hydrogels were taken before and after in-situ synthesis of the Ag-NPs in order to verify possible changes in the main and side chains of the matrix after irradiation (Figure 9). ${ }^{13} \mathrm{C}$ peaks for the carbons of PNIPAM and corresponding nanocomposite are well resolved. The most downfield peak 

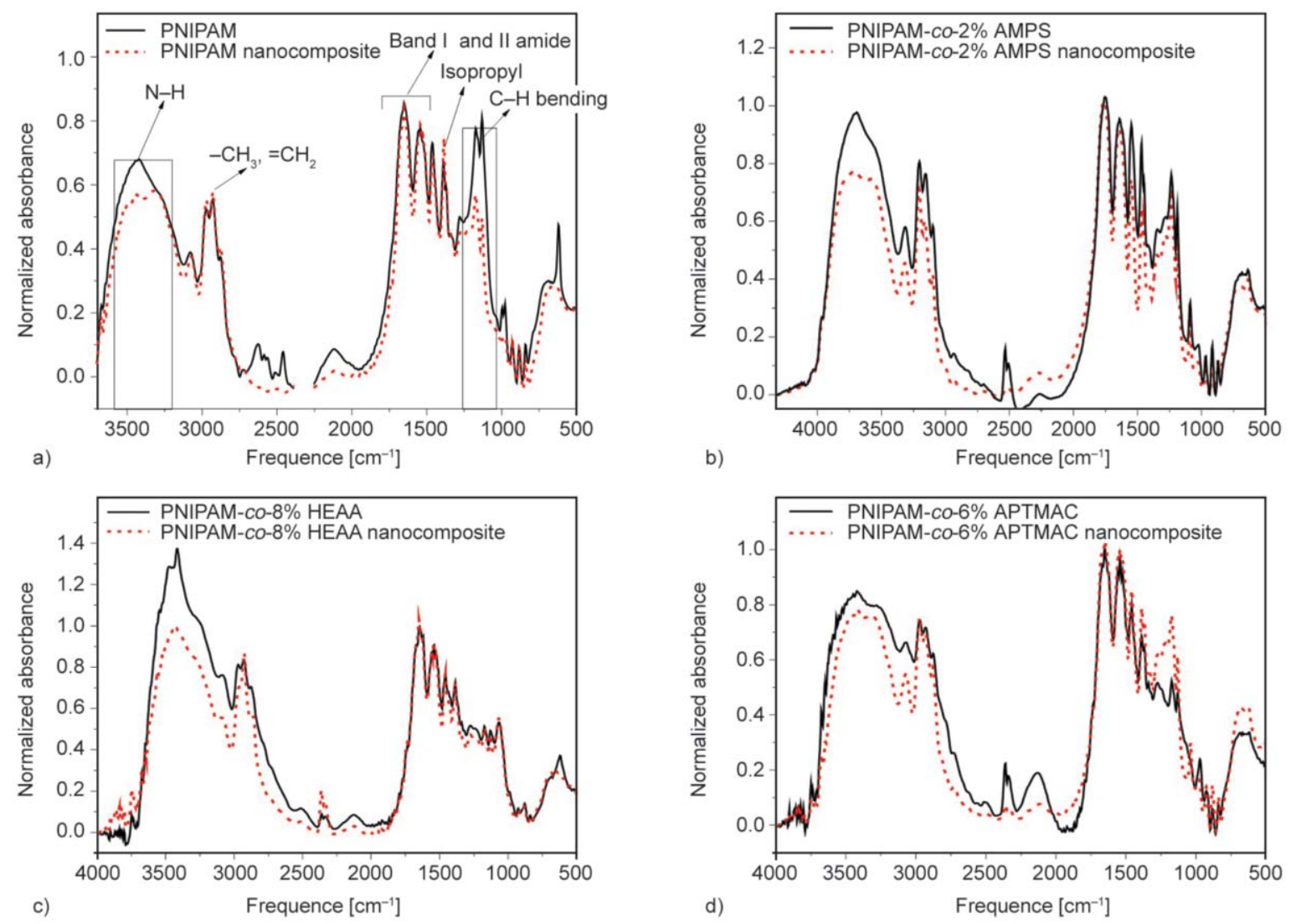

Figure 8. FTIR in solid-state of hydrogels and their corresponding nanocomposites obtained at $8 \mathrm{~h}$ of UV-irradiation, a) PNIPAM, b) PNIPAM-co-2\% AMPS, c) PNIPAM-co-8\% HEAA, d) PNIPAM-co-6\% APTMAC

of Figure 9 can be assigned to the carbonyl carbon $(\mathrm{C}=\mathrm{O})(175 \mathrm{ppm})$. The other peaks can be assigned to the main-chain and side chain methine $(\mathrm{CH})$ (41.6 ppm), methylene $\left(\mathrm{CH}_{2}\right)$ (34 ppm) and methyl $\left(\mathrm{CH}_{3}\right)$ carbon atoms of isopropyl groups $(23 \mathrm{ppm})$ [29].

It can be noticed that the typical signals of hydrogels and corresponding nanocomposite after irradiation are the same. So the carbon main chain is not chemically affected during the photoreduction process of $\mathrm{Ag}^{+}$ions [30, 31].

\subsection{Physicochemical characterization of nanocomposites}

\subsubsection{Swelling capacity}

Swelling capacity of hydrogels and nanocomposites in water at $\mathrm{pH} 6.5$ are compared. Figure 10 shows the swelling kinetic of nanocomposites obtained after $42 \mathrm{~h}$ of irradiation. Evidently, NPs formation affects the swelling capacity of each hydrogel and depends on chemical composition of matrix.

For non-ionic hydrogels (PNIPAM and PNIPAM-co$8 \%$ HEAA), swelling kinetic seems to be lightly affected by Ag-NPs presence. The initial slope of swelling seems to increase but maximum swelling capacity is reduced in non-ionic nanocomposites with regarded to original hydrogel. It seems that Ag-NPs are acting as crosslinking points or mechanical load. In ionic matrixes the presence of NPs remarkably affects the $\% S w_{(\text {eq }}$ only in case of cationic nanocomposite where $\% S w_{(\mathrm{eq})}$ drastically decreases perhaps due to high Ag-NPs concentration. Swelling of the anionic hydrogel is not altered because the Ag-NPs loading may be lower than in other nanocomposites.

\subsubsection{Volume phase transition temperature (VPTT)}

DSC experiences could give even more information about the new internal interactions formed inside hydrogel after $\mathrm{Ag}^{+}$ions in-situ photoreduction. Nanocomposite samples obtained at $8 \mathrm{~h}$ of irradiation in $0.01 \mathrm{M}$ of $\mathrm{AgNO}_{3}$ were analyzed.

The VPTT of each hydrogel and nanocomposites were calculated as the midpoint of the transition band. Each sample was run three times to determine the average values showed in Table 4 .

It is demonstrated that the presence of monomers more hydrophilic than NIPAM increases the VPTT 

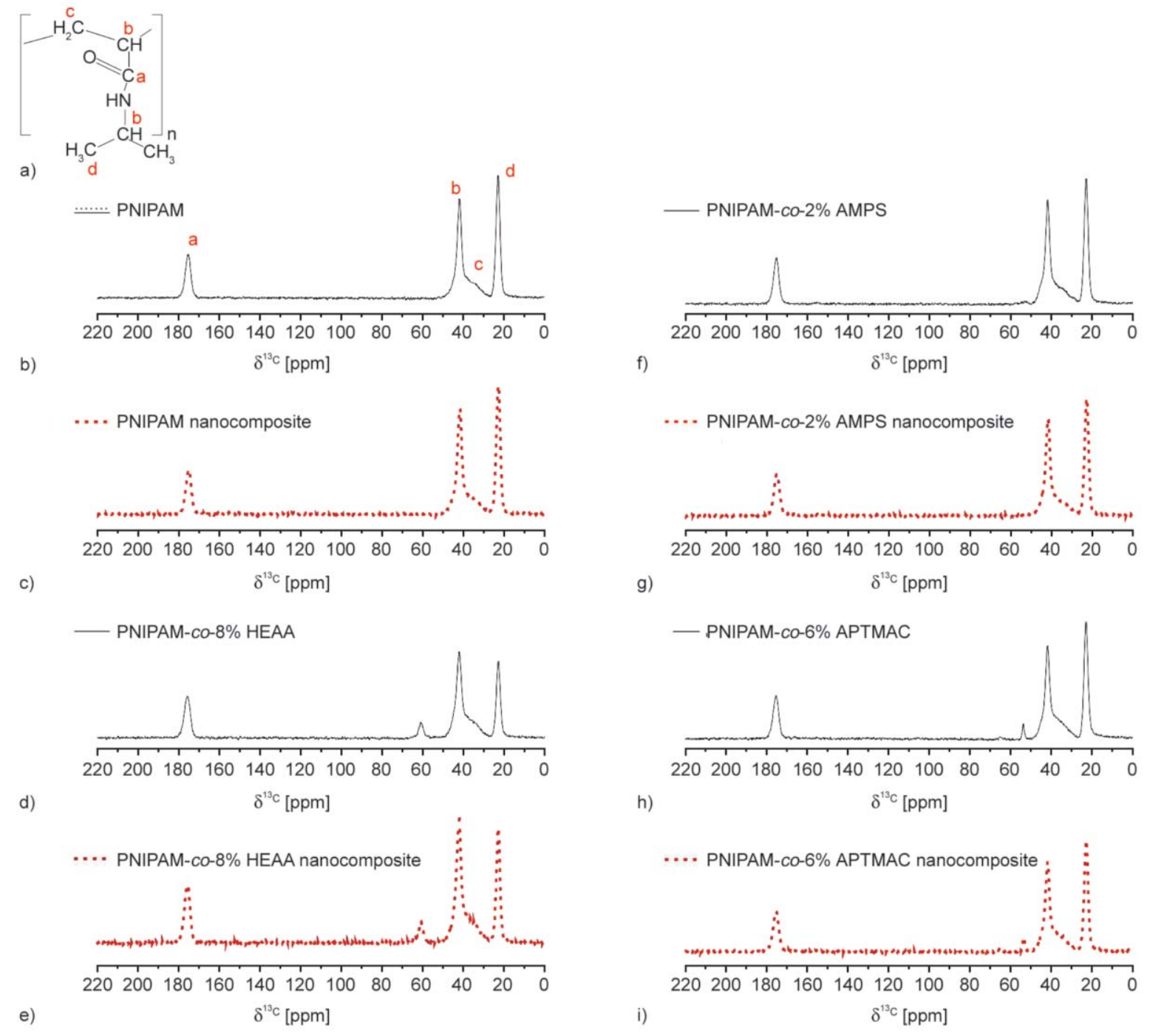

Figure 9. ${ }^{13} \mathrm{C}$ NMR spectrums in solid-state of hydrogels and corresponding nanocomposites obtained at $8 \mathrm{~h}$ of irradiation, a) peaks assigned to carbon atoms of PNIPAM structure, b) PNIPAM, c) PNIPAM nanocomposite, d) PNIPAMco-8\% HEAA, e) PNIPAM-co-8\% HEAA nanocomposite, f) PNIPAM-co-2\% AMPS, g) PNIPAM-co-2\% AMPS nanocomposite, h) PNIPAM-co-6\% APTMAC, i) PNIPAM-co-6\% APTMAC nanocomposite

regarding PNIPAM [32]. In addition, the changes observed in corresponding nanocomposites with regard to pure matrix could be given by the interactions

present between Ag-NPs and matrix but the change is not proportional to Ag-NPs grams present in matrix. Possibly, the swelling kinetic and VPTT changes

Table 4. Volume phase transition temperature (VPTT), milligrams Ag-NPs per gram of hydrogel, temperature variation $\left(\Delta T_{\mathrm{VPTT}}\right)$ between nanocomposite and respective hydrogel and its ratio to the amount of NPs $(\Delta T / \mathrm{mg}$ Ag-NPs). Nanocomposites were swollen in $0.01 \mathrm{M}$ of $\mathrm{AgNO}_{3}$ solution with $8 \mathrm{~h}$ of irradiation.

\begin{tabular}{|c|c|c|c|c|}
\hline HYDROGELS & $\begin{array}{l}\text { VPTT }^{*} \\
{\left[{ }^{\circ} \mathrm{C}\right]} \\
\end{array}$ & mg Ag-NPs/g hydrogel & $\Delta \boldsymbol{T}_{\mathrm{VPTT}}$ & $\Delta T / \mathrm{mg}$ Ag-NPs \\
\hline $\begin{array}{l}\text { PNIPAM } \\
\text { PNIPAM nanocomposite }\end{array}$ & $\begin{array}{l}32.0 \\
36.8\end{array}$ & 47 & 4.8 & 0.102 \\
\hline $\begin{array}{l}\text { PNIPAM-co- } 8 \% \text { HEAA } \\
\text { PNIPAM-co- } 8 \% \text { HEAA nanocomposite }\end{array}$ & $\begin{array}{l}41.7 \\
44.0\end{array}$ & 5 & 2.3 & 0.460 \\
\hline $\begin{array}{l}\text { PNIPAM-co-2\% AMPS } \\
\text { PNIPAM-co-2\% AMPS nanocomposite }\end{array}$ & $\begin{array}{l}35.8 \\
38.1\end{array}$ & 14 & 2.3 & 0.160 \\
\hline $\begin{array}{l}\text { PNIPAM-co-6\% APTMAC } \\
\text { PNIPAM-co-6\% APTMAC nanocomposite }\end{array}$ & $\begin{array}{l}75.5 \\
75.6\end{array}$ & 25 & 0.1 & 0.004 \\
\hline
\end{tabular}

* DS: \pm 0.2 . 

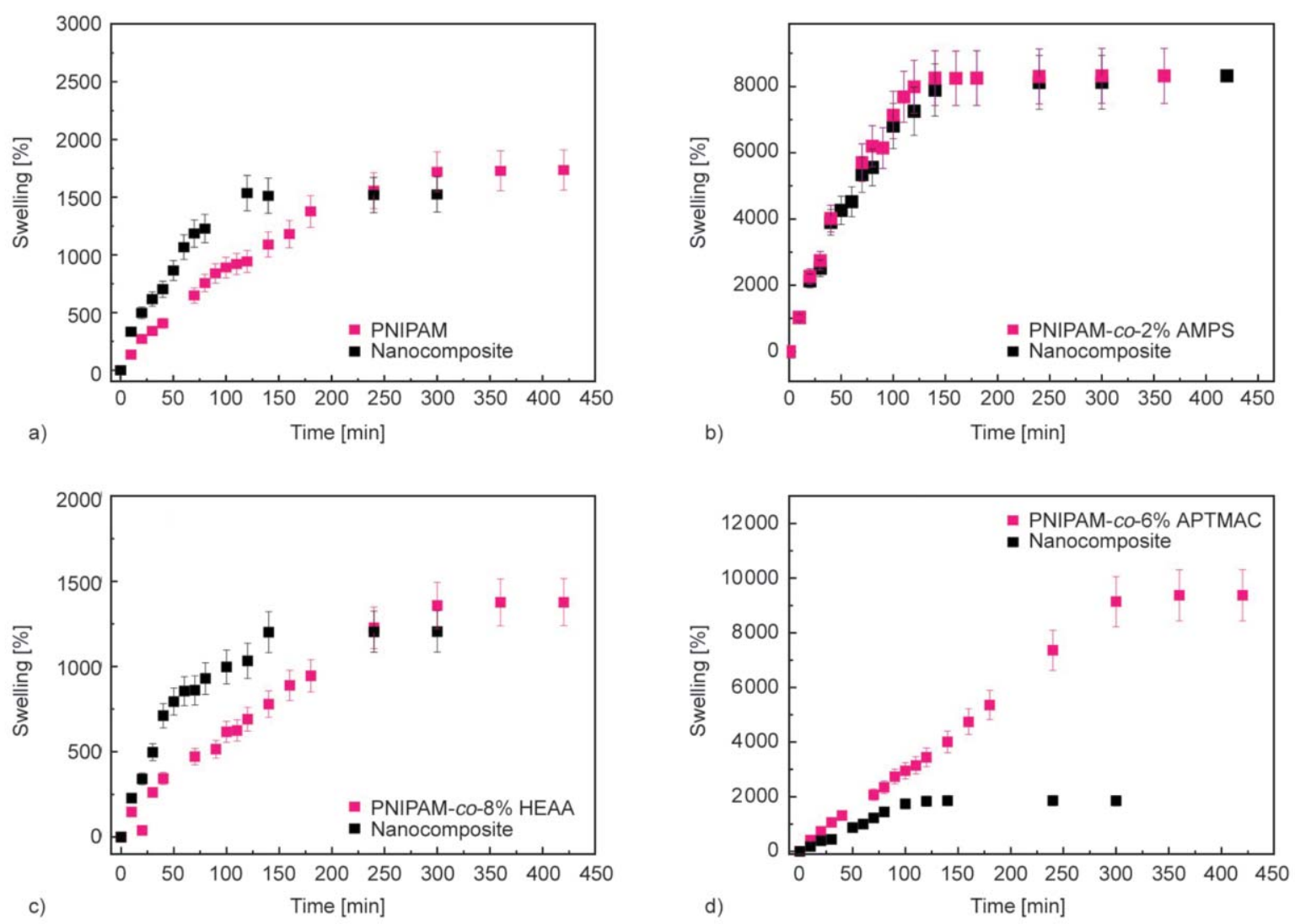

Figure 10. Swelling kinetic in water ( $\mathrm{pH}$ 6.5) of hydrogels and nanocomposites obtained at $42 \mathrm{~h}$ of irradiation, a) PNIPAM, b) PNIPAM-co- $2 \%$ AMPS, c) PNIPAM-co- $8 \%$ HEAA, d) PNIPAM-co-6\% APTMAC

are mainly related to the superficial area of agglomerates.

The coordination between Ag-NPs and nitrogen atoms of the amides, hydroxyl groups or carbonyl oxygen in PNIPAM seem to increase VPTT as a consequence of the immobilization of polymer on the NPs surface or vice versa [23].

Taking into account the change of VPTT $(\Delta T)$ between the nanocomposite and the respective hydrogel, and its ratio to the amount of NPs ( $\Delta T / \mathrm{mg}$ Ag-NPs), it is possible to conclude that the interactions of $\mathrm{Ag}$ NPs with PNIPAM are strong. While interactions take place mainly with carbonyl and nitrogen electrons of PNIPAM, the presence of co-monomers also has an important role on the interaction and stabilization of Ag-NPs. The presence of a large dispersion of small nanoparticles (Figure 6e, 6f) with a big surface area allows a large interaction with polymer chains.

In case of PNIPAM-co-6\%APTMAC matrix, the value of $\Delta T$ indicates that the cationic groups avoid the interaction between matrix and Ag-NPs. It is possible that Ag-NPs tend to be agglomerated among them which coincides with image TEM (Figure 6c, 6d) where bigger agglomerates are observed.
Higher values of $\Delta T / \mathrm{mg}$ Ag-NPs are observed when hydroxyl groups of HEAA and sulfonic groups of AMPS co-monomers are present. This indicates that the interactions of matrix with Ag-NPs are even more important. It may be due to Ag-NPs and agglomerates of smaller sizes (Figure 6e, 6f).

\subsubsection{Release capacity of NPs}

All synthesized hydrogels have the capacity to absorb $\mathrm{Ag}^{+}$ions, and nanocomposites with high load of Ag-NPs can be obtained by UV irradiation. In order to apply these nanocomposites as antibacterial systems, the release capacity of $\mathrm{Ag}$ in physiologic solution at $\mathrm{pH} 7.4$ was studied.

Experiments were carried out with nanocomposites obtained by swelling in $\mathrm{AgNO}_{3} 0.01 \mathrm{M}$ solution and $8 \mathrm{~h}$ of irradiation. These samples were placed on glass tube with $3 \mathrm{~mL}$ of physiological solution $0.85 \%$ $p / v \mathrm{NaCl}$ and the release was followed by UV-visible spectroscopy employing a reduced optical step cell $(0.5 \mathrm{~mL})$. Aliquots were taken every $2 \mathrm{~h}$; analyzed and then these aliquots were turned back to the vial. In Figure 11a, UV-visible spectra after each nanocomposite were immersed during $8 \mathrm{~h}$ in physiological 

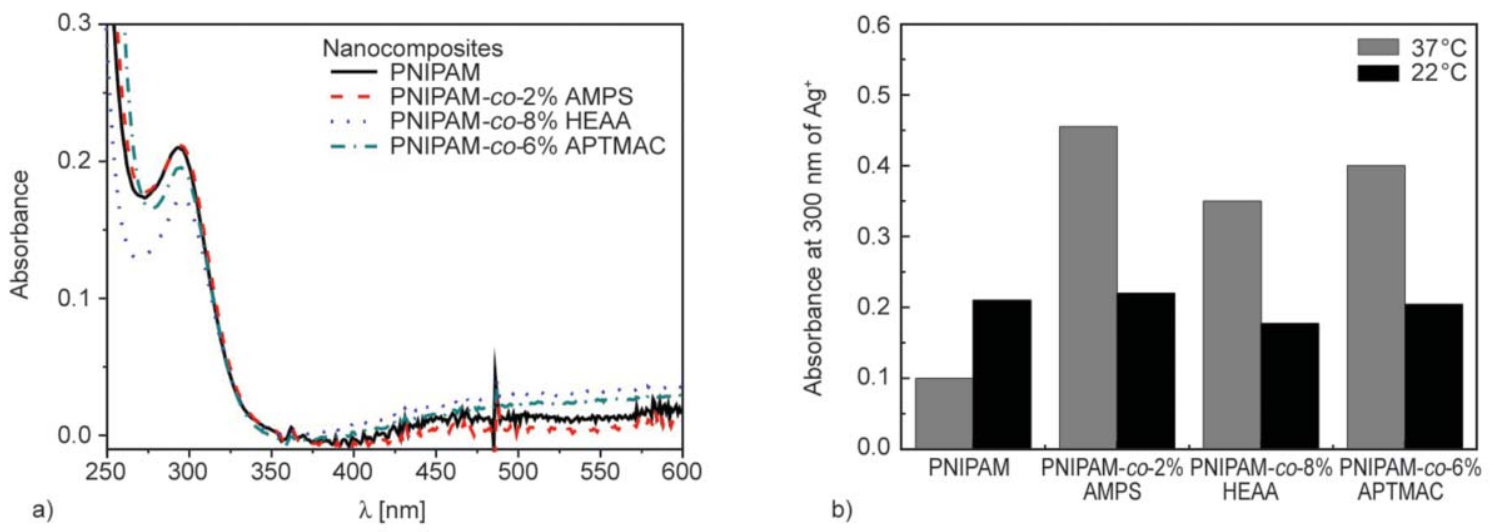

Figure 11. a) UV-visible spectra of physiological solutions at $\mathrm{pH} 7.4 \mathrm{after} 8 \mathrm{~h}$ nanocomposite immersion at room temperature $\left(22 \pm 1^{\circ} \mathrm{C}\right)$. b) Absorbance at $300 \mathrm{~nm}$ of $\mathrm{Ag}^{+}$ions released from the nanocomposites after $8 \mathrm{~h}$ immersion in physiological solution at $22 \pm 1$ and $37 \pm 1^{\circ} \mathrm{C}$.

solution, show intense absorption bands with maximum at ca. $300 \mathrm{~nm}$ and wide bands with intensity almost negligible from $400 \mathrm{~nm}$. The last band could correspond to a few released Ag-NPs while the very intense bands at $300 \mathrm{~nm}$ mainly correspond to $\mathrm{Ag}^{+}$ions or small Ag clusters [14]. However, it was reported that very small Ag-NPs $\sim 5 \mathrm{~nm}$ present an intense sharp peak at $393 \mathrm{~nm}$ being the band intensity very low at $270-300 \mathrm{~nm}$ [33]. Therefore, the in-
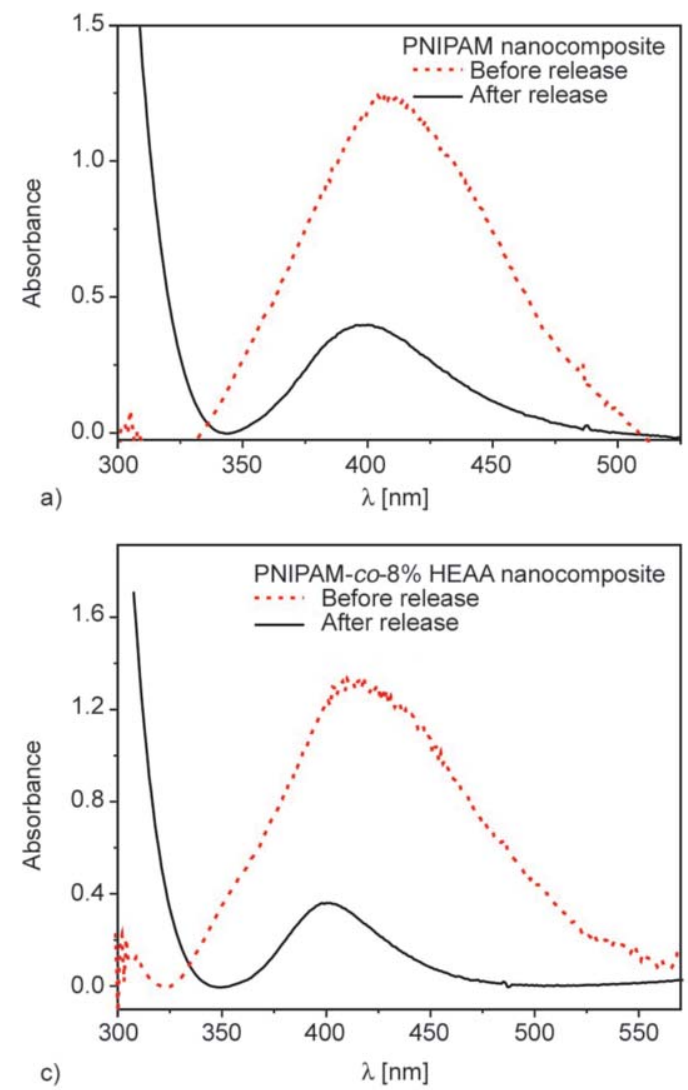

tensity difference between bands in figure 11a indicates that the released species are mainly $\mathrm{Ag}^{+}$ions. Figure $11 \mathrm{~b}$ shows the absorbance at $300 \mathrm{~nm}$ of physiological solutions after $8 \mathrm{~h}$ of immersion for each nanocomposite. At the same time, temperature effect on the release at 22 and $37^{\circ} \mathrm{C}$ is shown. Release $\mathrm{Ag}^{+}$ ions at $22^{\circ} \mathrm{C}$ tends to be similar for each composite while ionic matrixes at $37^{\circ} \mathrm{C}$ release $\mathrm{Ag}^{+}$ions faster than neutral hydrogels. PNIPAM slow down the re-
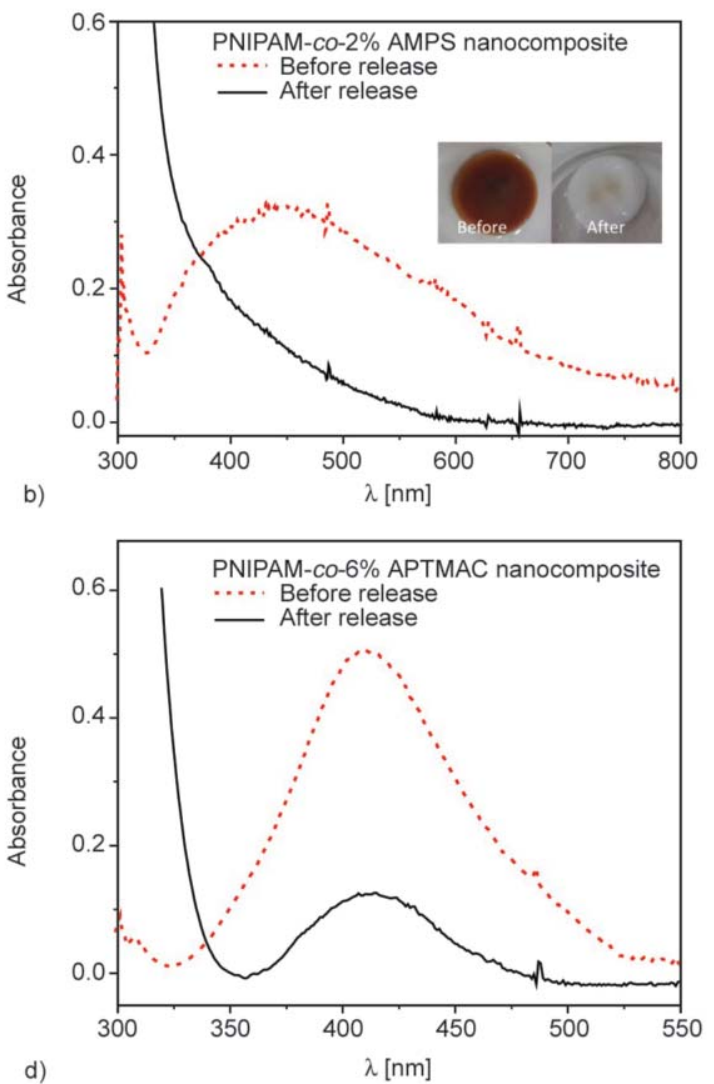

Figure 12. UV-visible spectra of nanocomposites before (short dash line) and after (solid line) $\mathrm{Ag}^{+}$ions released after $36 \mathrm{~h}$ at $22 \pm 1{ }^{\circ} \mathrm{C}$, a) PNIPAM, b) PNIPAM-co-2\% AMPS, c) PNIPAM-co- $8 \%$ HEAA, d) PNIPAM-co- $6 \%$ APTMAC 
lease rate possibly because matrix is collapsed on this temperature condition.

Evidently, in spite of the fact that ionic matrixes have Ag-NPs of different sizes and forms, the release kinetic of nanocomposites is quite similar. Figure 12 shows the spectra of nanocomposites before and after $36 \mathrm{~h}$ immersion in the physiological solution. Although the release of $\mathrm{Ag}^{+}$ions is observed for all studied nanocomposites, only in case of PNIPAMco-2\% AMPS the complete loss of color is notable. This is also demonstrated by photography of nanocomposite pills insert.

Considering the relation of Ag-NPs maximum absorbance before and after $36 \mathrm{~h}$ immersion in physiological solution, the release rate order $(R R O)$ of each nanocomposite could be estimated. Thereby, the release rate follows the order: PNIPAM-co- $2 \%$ AMPS $(R R O=\infty)>$ PNIPAM-co- $6 \%$ APTMAC $(R R O=4.2)>$ PNIPAM- $c o-8 \%$ HEAA $(R R O=3.7)$ $>$ PNIPAM $(R R O=3.1)$. Similar tendencies are observed at both reported temperatures $\left(22\right.$ and $\left.37^{\circ} \mathrm{C}\right)$. The results could indicate that the release rate of $\mathrm{Ag}^{+}$ ions could be controlled by chemical composition of hydrogel matrix. It is noteworthy that the hydrogel matrices are able to synthesize and contain Ag-NPs (which are not spontaneously released) in solution, while they release $\mathrm{Ag}^{+}$ions in physiological medium. Finally, the retain/release process could be regulated with the chemical composition of matrix.

\subsection{Antibacterial activity of nanocomposites}

The in vitro antibacterial screening of hydrogels and their nanocomposites have been carried out against Pseudomonas aeruginosa (Gram-negative) growth in agar culture plates. It can be seen in Figure 13 that hydrogels without Ag-NPs (control) do not induce inhibition zone indicating that the bacterial growth on hydrogels is not inhibited, while hydrogel containing silver nanoparticles has high antibacterial properties since inhibition halos around nanocomposites are observed.

The antibacterial activity shown in Table 5 is a manifestation of the release of $\mathrm{Ag}^{+}$ions from the different nanocomposites as it was previously demonstrated. The inhibition area of different nanocomposites after $42 \mathrm{~h}$ of culture follows the order: PNIPAM-co-2\%

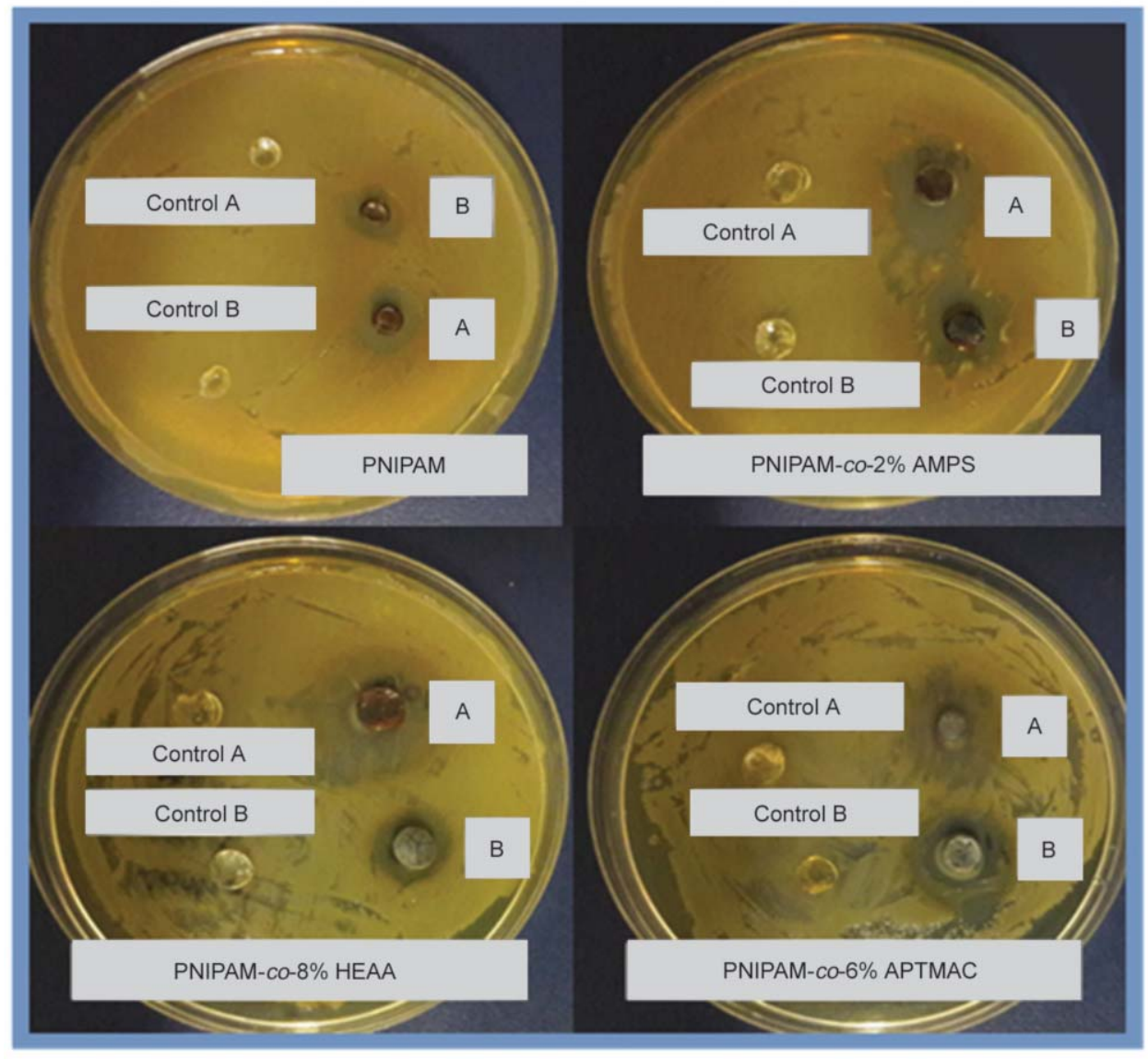

Figure 13. Photographs of bacterial grown of Pseudomonas aeruginosa after $48 \mathrm{~h}$ culture time on hydrogels (Control) and Ag-NPs nanocomposites (irradiated at $24 \mathrm{~h}$ ). (A) Nanocomposite irradiated in $0.01 \mathrm{M} \mathrm{AgNO}_{3}$ solution, (B) nanocomposite irradiated in $0.1 \mathrm{M} \mathrm{AgNO}_{3}$ solution. 
Table 5. In vitro antimicrobial activity by agar method diffusion of tested materials. Inhibition halo diameters after $48 \mathrm{~h}$ culture at $37^{\circ} \mathrm{C}$.

\begin{tabular}{|c|c|c|}
\hline Nanocomposites & $\begin{array}{c}\text { Halos }\left(0.01 \mathrm{M} \mathrm{AgNO}_{3}\right) \\
{[\mathrm{cm}]}\end{array}$ & $\begin{array}{c}\text { Halos }\left(0.1 \mathrm{M} \mathrm{AgNO}_{3}\right) \\
{[\mathrm{cm}]}\end{array}$ \\
\hline PNIPAM & $1.35 \pm 0.15$ & $1.2 \pm 0.2$ \\
\hline PNIPAM-co- $8 \%$ HEAA & $1.40 \pm 0.05$ & $1.3 \pm 0.1$ \\
\hline PNIPAM-co- $\%$ AMPS & $2.00 \pm 0.05$ & $1.7 \pm 0.2$ \\
\hline PNIPAM-co-6\% APTMAC & $1.70 \pm 0.20$ & $1.4 \pm 0.2$ \\
\hline
\end{tabular}

AMPS $>$ PNIPAM-co- $6 \%$ APTMAC $>$ PNIPAM- $c$ $8 \%$ HEAA $>$ PNIPAM. Noteworthy, the order coincides with release rate of $\mathrm{Ag}^{+}$ions previously observed.

Despite the fact that after $42 \mathrm{~h}$ of irradiation the NPs are likely to be agglomerated, the nanocomposites show high antibacterial capacity by releasing of $\mathrm{Ag}^{+}$ ions. In this way, the antibacterial properties of the nanocomposites synthesized are not size dependent of nanoparticles and the agglomerations would not be a problem. Higher effect seems to be observed in PNIPAM-co-2\% AMPS and PNIPAM-co-6\% APTMAC nanocomposites which release faster $\mathrm{Ag}^{+}$ ions according to Figure 11, even with less loaded NPs amount (Figure 7). In addition, salt and temperature effects could induce the phase transition of nanocomposites in culture conditions and the materials could be collapsed (Figure 13).

It is noteworthy that a high loading of Ag-NPs inside the matrix does not increase the antibacterial capacity of nanocomposite. It is likely that less agglomerated NPs have larger active areas and release ions more effectively. However, to confirm this conclusion, a kinetic study of $\mathrm{Ag}^{+}$ions release versus inhibition halos could be necessary.

\section{Conclusions}

It was demonstrated that matrixes based on PNIPAM and co-polymers are able to load $\mathrm{Ag}^{+}$ions and form Ag-NPs by photoreduction in the absence of other additives (reductant or stabilizer agents). Chemical composition of matrix governs the partition capacity and reduction of $\mathrm{Ag}^{+}$ions, as well as the stabilization of the Ag-NPs synthesized inside the hydrogels.

FTIR and ${ }^{13} \mathrm{C}$ NMR results indicate that the functional groups of the matrixes act as reductants since an effect of chemical composition of the hydrogel on the Ag-NPs formation is observed. In addition, release rate order of $\mathrm{Ag}^{+}$ions by nanocomposites could be estimated in function of chemical composition of matrix, being another indication of matrix stabilizer character.

The formation of agglomerates can be avoided by controlling irradiation time and initial concentration of the precursor ion. However, the Ag-NP agglomerations affect neither the release of $\mathrm{Ag}^{+}$ions or antibacterial capacity of nanocomposite. The Ag-NPs are encapsulated inside the hydrogel and the hydrogel avoids their dispersion and controls the antibacterial agent $\left(\mathrm{Ag}^{+}\right.$ions) release rate.

Some systems are built in order to release Ag-NPs and induce bacterial death by toxicity $[10,34]$. However, these nanocomposites can avoid the cytotoxic effect of Ag-NPs [35] since only $\mathrm{Ag}^{+}$ions are released. The controlled release of $\mathrm{Ag}^{+}$ions could be regulated by chemical composition of matrix. Therefore, and having demonstrated that matrix based on PNIPAM are biocompatible [11], these controlled release systems could be applied as antibacterial cell scaffolds for future biomedical applications or bioprotective materials able to maintain a pollution free system (cells, foods, etc).

\section{Acknowledgements}

This work was funded by FONCYT (PICT 2013-2716), CONICET (PIP 2013-15: 11220120100529CO) and SeCyTUNRC (PPI 2016-2018). M. Monerris thanks CONICET for graduate research fellowships. The help of Luciana Fernandez with the SEM images is gratefully acknowledged.

\section{References}

[1] Peppas N. A., Barr-Howell B. D.: Characterization of the crosslinked structure of hydrogels. in 'Hydrogels in medicine and pharmacy' (ed.: Peppas N. A.) CRC, Press Boca Raton, Vol 1, 27-56 (1986).

[2] Mattiasson B., Kumar A., Galaev Y. I.: Macroporous polymers: Production properties and biotechnological/ biomedical applications. Taylor and Francis, Boca Raton (2010). 
[3] Hu X., Gong X.: A new route to fabricate biocompatible hydrogels with controlled drug delivery behavior. Journal of Colloid and Interface Science, 470, 62-70 (2016). https://doi.org/10.1016/j.jcis.2016.02.037

[4] Martínez M. V., Bongiovanni Abel S., Rivero R., Miras M. C., Rivarola C. R., Barbero C. A.: Polymeric nanocomposites made of a conductive polymer and a thermosensitive hydrogel: Strong effect of the preparation procedure on the properties. Polymer, 78, 94-103 (2015). https://doi.org/10.1016/j.polymer.2015.09.054

[5] Molina M. A., Rivarola C. R., Miras M. C., Lescano D., Barbero C. A.: Nanocomposite synthesis by absorption of nanoparticles into macroporous hydrogels. Building a chemomechanical actuator driven by electromagnetic radiation. Nanotechnology, 22, 245504/1-245504/8 (2011). https://doi.org/10.1088/0957-4484/22/24/245504

[6] Pourjavadi A., Abedin-Moghanaki A.: Ultrafast and efficient removal of cationic dyes using a magnetic nanocomposite based on functionalized cross-linked poly (methylacrylate). Reactive and Functional Polymers, 105, 95-102 (2016). https://doi.org/10.1016/j.reactfunctpolym.2016.05.016

[7] Bongiovanni Abel S., Molina M. A., Rivarola C., Kogan M., Barbero C.: Smart polyaniline nanoparticles with thermal and photothermal sensitivity. Nanotechnology, 25, 495602/1-495602/10 (2014).

https://doi.org/10.1088/0957-4484/25/49/495602

[8] Kumar C. S. S. R.: Metallic nanomaterials. Wiley, Weinheim (2009).

[9] Morones J. R., Elechiguerra J. L., Camacho A., Holt K., Kouri J. B., Ramírez J. T., Yacaman M. J.: The bactericidal effect of silver nanoparticles. Nanotechnology, 16, 2346/1-2346/9 (2005).

https://doi.org/10.1088/0957-4484/16/10/059

[10] Rivero R. E., Alustiza F., Rodríguez N., Bosch P., Miras M. C., Rivarola C. R., Barbero C. A.: Effect of functional groups on physicochemical and mechanical behavior of biocompatible macroporous hydrogels. Reactive and Functional Polymers, 97, 77-85 (2015). https://doi.org/10.1016/j.reactfunctpolym.2015.10.011

[11] Kyriacou S. V., Brownlow W. J., Xu X-H. N.: Using nanoparticle optics assay for direct observation of the function of antimicrobial agents in single live bacterial cells. Biochemistry, 43, 140-147 (2004). https://doi.org/10.1021/bi0351110

[12] Rao K. M., Kumar A., Haider A., Han S. S.: Polysaccharides based antibacterial polyelectrolyte hydrogels with silver nanoparticles. Materials Letters, 184, 189 192 (2016). https://doi.org/10.1016/j.matlet.2016.08.043

[13] Kutsevol N., Chumachenko V., Rawiso M., Shyichuk A.: Green synthesis of silver nanoparticles using dextran-graft-polyacrylamide as template. Micro and Nano letters, 11, 256-259 (2016). https://doi.org/10.1049/mnl.2015.0547
[14] Stamplecoskie K. G., Scaiano J. C.: Light emitting diode irradiation can control the morphology and optical properties of silver nanoparticles. Journal of the American Chemical Society, 132, 1825-1827 (2010). https://doi.org/10.1021/ja910010b

[15] Bhui D. K., Bar H., Sarkar P., Sahoo G. P., De S. P., Misra A.: Synthesis and UV-vis spectroscopic study of silver nanoparticles in aqueous SDS solution. Journal of Molecular Liquids, 145, 33-37 (2009). https://doi.org/10.1016/j.molliq.2008.11.014

[16] Yamamoto M., Kashiwagi Y., Nakamoto M.: Size-controlled synthesis of monodispersed silver nanoparticles capped by long-chain alkyl carboxylates from silver carboxylate and tertiary amine. Langmuir, 22, 85818586 (2006). https://doi.org/10.1021/la0600245

[17] He Y., Huang G., Pan Z., Liu Y., Gong Q., Yao C., Gao J.: Polyelectrolyte induced formation of silver nanoparticles in copolymer hydrogel and their application as catalyst. Materials Research Bulletin, 70, 263-271 (2015). https://doi.org/10.1016/j.materresbull.2015.04.028

[18] Evanoff D. D. Jr., Chumanov G.: Size-controlled synthesis of nanoparticles. 1. 'Silver-only' aqueous suspensions via hydrogen reduction. Journal of Physical Chemistry $\mathrm{B}, \mathbf{1 0 8}, 13948-13956$ (2004).

https://doi.org/10.1021/jp047565s

[19] Martínez M. V., Rivarola C. R., Miras M. C., Barbero C.: A colorimetric iron sensor based on the partition of phenanthroline complexes into polymeric hydrogels. Combinatorial synthesis and high throughput screening of the hydrogel matrix. Sensors and Actuators B: Chemical, 241, 19-32 (2017). https://doi.org/10.1016/j.snb.2016.10.013

[20] Chandrika Pooma K. S. V., Singh A., Rathore A., Kumar A.: Novel cross linked guar gum- $g$-poly(acrylate) porous superabsorbent hydrogels: Characterization and swelling behaviour in different environments. Carbohydrate. Polymers, 149, 175-185 (2016). https://doi.org/10.1016/j.carbpol.2016.04.077

[21] Xu G., Gao S., Ji X., Zhang X.: Characterization and synthesis mechanism of nanosilver/pamps composites by microwave. Soft Nanoscience Letters, 4, 15-23 (2014). https://doi.org/10.4236/snl.2014.42003

[22] Maciollek A., Ritter H.: One pot synthesis of silver nanoparticles using a cyclodextrin containing polymer as reductant and stabilizer. Beilstein Journal Nanotechnol, 5, 380-385 (2014).

https://doi.org/10.3762/bjnano.5.44

[23] Balan L., Malval J-P., Schneider R., Le Nouen D., Lougnot D-J.: In-situ fabrication of polyacrylate-silver nanocomposite through photoinduced tandem reactions involving eosin dye. Polymer, 51, 1363-1369 (2010). https://doi.org/10.1016/j.polymer.2009.05.003 
[24] Malval J-P., Jin M., Balan L., Schneider R., Versace DL., Chaumeil H., Defoin A., Soppera O.: Photoinduced size-controlled generation of silver nanoparticles coated with carboxylate-derivatized thioxanthones. Journal of Physical Chemistry C, 114, 10396-10402 (2010). https://doi.org/10.1021/jp102189u

[25] Shon Y-S., Cutler E.: Aqueous synthesis of alkanethiolate-protected $\mathrm{Ag}$ nanoparticles using bunte salts. Langmuir, 20, 6626-6630 (2004).

https://doi.org/10.1021/la049417z

[26] Doty R. C., Tshikhudo T. R., Brust M., Fernig D. G.: Extremely stable water-soluble Ag nanoparticles. Chemistry of Materials, 17, 4630-4635 (2005).

https://doi.org/10.1021/cm0508017

[27] Hiramatsu H., Osterloh F. E.: A simple large-scale synthesis of nearly monodisperse gold and silver nanoparticles with adjustable sizes and with exchangeable surfactants. Chemistry of Material, 16, 2509-2511 (2004). https://doi.org/10.1021/cm049532v

[28] Socrates G.: Infrared and Raman characteristic group frequencies: Tables and charts. Wiley, New York (2001).

[29] Ohta H., Ando I.: A ${ }^{13}$ C PST/MAS NMR study of poly ( $N$-isopropylacrylamide) in solution and in the gel phase. Journal of Molecular Structure, 245, 391-397 (1991). https://doi.org/10.1016/0022-2860(91)87113-V

[30] Jiang X., Zhai S., Jiang X., Lu G., Huang X.: Synthesis of PAA-g-PNIPAM well-defined graft polymer by sequential RAFT and SET-LRP and its application in preparing size-controlled super-paramagnetic $\mathrm{Fe}_{3} \mathrm{O}_{4}$ nanoparticles as a stabilizer. Polymer, 55, 3703-3712 (2014).

https://doi.org/10.1016/j.polymer.2014.05.050
[31] Kametani S., Sekine S., Ohkubo T., Hirano T., Ute K., Cheng H. N., Asakura T.: NMR studies of water dynamics during sol-to-gel transition of poly ( $N$-isopropylacrylamide) in concentrated aqueous solution. Polymer, 109, 287-296 (2017).

https://doi.org/10.1016/j.polymer.2016.12.063

[32] Molina M. A., Rivarola C. R., Barbero C. A.: Effect of copolymerization and semi-interpenetration with conducting polyanilines on the physicochemical properties of poly( $N$-isopropylacrylamide) based thermosensitive hydrogels. European Polymer Journal, 47, 1977-1984 (2011).

https://doi.org/10.1016/j.eurpolymj.2011.07.015

[33] Agnihotri S., Mukherji S., Mukherji S.: Size-controlled silver nanoparticles synthesized over the range 5$100 \mathrm{~nm}$ using the same protocol and their antibacterial efficacy. RSC Advances, 4, 3974-3983 (2014). https://doi.org/10.1039/C3RA44507K

[34] He X., Wang F., Liu H., Li J., Niu L.: Synthesis of quartz crystals supporting Ag nanoparticle powder with enhanced antibacterial properties. Surfaces and Interfaces, 6, 122-126 (2017). https://doi.org/10.1016/j.surfin.2017.01.002

[35] Liu X., Man H. C.: Laser fabrication of Ag-HA nanocomposites on Ti6Al4V implant for enhancing bioactivity and antibacterial capability. Materials Science and Engineering: C, 70, 1-8 (2017). https://doi.org/10.1016/j.msec.2016.08.059 